\title{
Strength development of soil-fly ash geopolymer: Assessment of soil, fly ash, alkali activators and water
}

\author{
Hsiao Yun Leong ${ }^{1}$, Dominic Ek Leong Ong ${ }^{2 *}$, Jay G. Sanjayan ${ }^{3}$, Ali Nazari ${ }^{4}$ \\ ${ }^{1}$ Ph.D scholar, Research Centre for Sustainable Technologies, Faculty of Engineering, Science \& Computing, Swinburne \\ University of Technology Sarawak Campus, 93350 Kuching, Sarawak, Malaysia. E-mail: hyleong@swinburne.edu.my \\ ${ }^{2}$ Associate Professor, Research Centre for Sustainable Technologies, Faculty of Engineering, Science \& Computing, Swinburne \\ University of Technology Sarawak Campus, 93350 Kuching, Sarawak, Malaysia. E-mail: elong@swinburne.edu.my \\ ${ }^{3}$ Professor, Centre for Sustainable Infrastructure, Faculty of Science, Engineering and Technology, Swinburne University of \\ Technology, PO Box 218, Hawthorn, Victoria 3122, Australia. E-mail: jsanjayan@swin.edu.au \\ ${ }^{4}$ ARC Future Fellowship, Centre for Sustainable Infrastructure, Faculty of Science, Engineering and Technology, Swinburne \\ University of Technology, PO Box 218, Hawthorn, Victoria 3122, Australia. E-mail: alinazari@swin.edu.au \\ * Corresponding author
}

\section{Abstract}

In this study, fly ash was added to residual soil to produce soil-fly ash geopolymer bricks. This study investigated the effects of fly ash/soil, alkali activator/ash, $\mathrm{Na}_{2} \mathrm{SiO}_{3} / \mathrm{KOH}$ (or $\mathrm{NaOH}$ ), additional water content, curing condition and curing temperature on the compressive strength of soil-fly ash geopolymer. The results showed that the optimum compressive strength was obtained when the ratios of alkali activator/ash, $\mathrm{Na}_{2} \mathrm{SiO}_{3} / \mathrm{KOH}$ (or $\mathrm{NaOH}$ ) and additional water were 0.6 , 0.5 and $10 \%$ respectively. Higher amount of alkali activators was required for strength development in soil-fly ash geopolymer than conventional fly ash-based geopolymers. The formation of the rigid structure at low ratios of alkali activator/ash and $\mathrm{Na}_{2} \mathrm{SiO}_{3} / \mathrm{KOH}$ (or $\mathrm{NaOH}$ ) was unlikely. Compressive strength decreased when additional water was increased. High curing temperature and long curing duration showed negative effect on strength development. The compressive strength of soil-fly ash geopolymer varied as different mixing sequences of raw materials were used, indicating the importance of the formation of geopolymer gel in the structure. 
29 Compressive strength results obtained in this study demonstrate that soil-fly ash geopolymer can be a potential alternative to traditional clay fired brick.

\section{Keyword}

Soil; fly ash; geopolymer; alkali activators; compressive strength

\section{Introduction}

Clay fired brick is commonly used as construction material. The making process requires firing process which is kilned under high temperature for strength development. During the firing process, it consumes high energy derived by burning charcoal to increase the temperature. Carbon dioxide emission due to high energy consumption pollutes the atmosphere by contributing to the greenhouse effect. Developing a greener material can effectively reduce the exposure of hazard to the surrounding environment, thus being more environmentally friendly. Different types of industrial by-product such as fly ash, sawdust, waste bricks, biomass waste and olive pomace ash have been reported and added into fired clay brick by other researchers (Bories et al. 2015; Casa and Castro 2014; Velasco et al. 2014a; Zhang 2013).

45

Fly ash, an aluminosilicate material, is an industrial by-product from the combustion of coal at power stations. Geopolymer, an inorganic aluminosilicate polymer, is produced by activating the aluminosilicate materials such as fly ash, bottom ash, metakaolin and slag in an alkaline environment at the low curing temperature (Davidovits 2008). Various types of alkali activator can be used to activate fly ash such as sodium hydroxide, sodium silicate, potassium hydroxide etc. (Criado et al. 2007; Heah et al. 2012; Nematollahi and Sanjayan 2014; Ryu et al. 2013) to 
produce geopolymer gel. The combined use of sodium hydroxide and sodium silicate as alkali activators for making geopolymer exhibited good compressive strength (Hardjito and Rangan 2005). The formation of three-dimensional polymer chains can be attributed to three main stages, i.e. dissolution of silica and alumina from the aluminosilicate source, reorganisation and polycondensation (Davidovits 2008). The formation of geopolymer gel in the structure was confirmed through the microstructure images (Komljenovi et al. 2010; Tennakoon et al. 2014), contributing to the strength development. Geopolymer has been used as a sustainable construction material in structural elements of buildings such as beams, columns and piles (Power Pile 2013; Sarker 2008; Shrest 2013; Uretek 2014), besides also being viable as a ground treatment method when mixed with weaker clayey soils (Cristelo et al. 2013; Cristelo et al. 2012; Zhang et al. 2013). Being an environmentally friendly construction material, the production of geopolymer emits $80 \%$ less carbon dioxide than manufacturing traditional Portland cement (Duxson et al. 2007).

Other than making fly ash based geopolymer, fly ash can be used to produce clay-fly ash geopolymer (Phetchuay et al. 2014; Sukmak et al. 2013a; Xu et al. 2005). Sukmak et al. (2013a) reported that the amount of alkali activators and fly ash/clay content correspond directly to its compressive strength. The maximum compressive strength was obtained at the ratio of alkali activator/ash of 0.5 to 0.6 and the ratio of $\mathrm{Na}_{2} \mathrm{SiO}_{3} / \mathrm{NaOH}$ of 0.7 . The increase of amorphous phase of $\mathrm{SiO}_{2}$ and the $\mathrm{Al}_{2} \mathrm{O}_{3}$ due to higher ratios of fly ash increases the strength capability (Lingling et al. 2005). However, $\mathrm{SiO}_{2}$ and $\mathrm{Al}_{2} \mathrm{O}_{3}$ in clay particles are mostly of the crystalline phase (Phetchuay et al. 2014), indicating the formation of geopolymer gel due to the chemical reaction amongst the clay particles and alkali activators is unlikely. The water content within the sample influent the compressive strength of geopolymer (Phetchuay et al. 2016). 
Diop et al. (2014) reported that different curing temperature and curing time led to different strength capability. High curing temperature and long curing time corresponded to higher compressive strength. The formation of geopolymer gel due to better geopolymerisation enhanced the strength capabilities (Phetchuay et al. 2014; Phummiphan et al. 2016a). The geopolymer structure became more rigid after curing for certain period in comparison to its early stage (Diop et al. 2011). This could be due to the geopolymer that formed became more stable as the curing time increased. Zhang et al. (2012) explained the importance of pre-curing process at room temperature. As water content within the sample evaporated during the pre-curing process, cracking at the later curing stage at high temperature was prevented. Hence, strength development was improved. The formation of sponge-like aluminosilicate species was observed amongst the clay particles in the geopolymer structure (Ogundiran and Kumar 2015). The formation of geopolymer gel in clay-fly ash geopolymer was confirmed through scanning electron microscopy by researchers (Diop et al. 2014; Phetchuay et al. 2014; Phummiphan et al. 2016b; Sukmak et al. 2013a; Xu et al. 2005). It bound the clay particles together thus forming a rigid structure (Diop et al. 2014). However, the morphology studies on the soil-fly ash geopolymer at different ratios of fly ash/soil and additional water content are found to be rather limited.

In this study, residual soil is used to produce soil-fly ash geopolymer. The main purpose of this study is to assess the effect of the ratio of fly ash/soil, the ratio of alkali activator/ash, the ratio of $\mathrm{Na}_{2} \mathrm{SiO}_{3} / \mathrm{KOH}$ ( or $\mathrm{NaOH}$ ), additional water content, curing condition and curing temperature on the compressive strength of soil-fly ash geopolymer. This study aims to develop further the 
application of fly ash other than producing the conventional fly ash-based geopolymer, utilizing the method, which is analogous to the brick-making industry to produce soil-fly ash geopolymer.

\section{Experimental Procedure}

\section{Materials}

Fly ash

In this study, Sarawak fly ash which is available in the local industry was used. It was obtained from Sejingkat Power Station, which is located in the Sarawak state capital of Kuching in Malaysia. Sarawak fly ash has been successfully used in a handful of studies (Leong et al. 2015; Leong et al. 2016a; Leong et al. 2016b). Table 1 shows the chemical compositions of the fly ash using WDX-ray Fluorescence Spectrometer (WD-XRF). It is classified as Class F type in accordance to ASTM-C618 (2005), containing low calcium content and hence having poor self-cementing properties. Alkali activators are essentially required to activate the fly ash content for geopolymerisation and strength development.

\section{Soil}

The residual soil was sourced from the outskirt of Kuching city, Malaysia. It is classified as reddish brown slightly sandy silt with a natural moisture content of $53 \%$. It consists of $11 \%$ gravel, $13 \%$ sand, $34 \%$ silt and $42 \%$ clay. The liquid limit, plastic limit and plasticity index of the residual soil are $66 \%, 36 \%$ and $30 \%$ respectively. The optimum moisture content (OMC) and the maximum dry density (MDD) of the residual soil are $47 \%$ and $1184 \mathrm{~kg} / \mathrm{m}^{3}$. The chemical compositions of the residual soil are tabulated in Table 1. It contains relatively lower $\mathrm{SiO}_{2}$ content but relatively higher $\mathrm{Al}_{2} \mathrm{O}_{3}$ and $\mathrm{Fe}_{2} \mathrm{O}_{3}$ contents than fly ash. Fig. 1 shows the morphologies of fly 

ash and soil under a scanning electron microscopy (SEM). As seen in the SEM images, fly ash mainly consists of spherical shape whereas soil shows irregular shapes and exhibits porous-like structures. The particle size distributions of both fly ash and soil are plotted in Fig. 2. It demonstrates that fly ash has much smaller particle sizes than soil. However, the latter has wider distributions of particle size. It is mainly due to the physical and chemical weathering processes of the parent rock to form the residual soil, making it behaves more heterogeneous rather than homogenous (Wesley 2010). The difference of particle size distributions of both fly ash and soil

127 is postulated to be an important factor for strength development, which will be discussed further 128 in the next section.

\section{Alkali activators}

$1318 \mathrm{M}$ potassium hydroxide $(\mathrm{KOH})$ solution and $8 \mathrm{M}$ sodium hydroxide $(\mathrm{NaOH})$ solution were 132 prepared (Leong et al. 2016a) from $\mathrm{KOH}$ pellets (brand: Merck) and $\mathrm{NaOH}$ pellets (brand: Hudson) 133 respectively. The combined use of potassium hydroxide or sodium hydroxide and sodium silicate $134\left(\mathrm{Na}_{2} \mathrm{SiO}_{3}\right)\left(17 \% \mathrm{Na}_{2} \mathrm{O}\right.$ and $35 \% \mathrm{SiO}_{2}$ by weight $)$ was used as the alkali activators in this study.

135 This combination is the most common used in practice in terms of cost effectiveness to produce 136 geopolymer with good compressive strength than the sole use of alkali silicate or hydroxide 137 (Hardjito \& Rangan 2005). High concentrations of alkali are essential to activate fly ash particles 138 to form geopolymer gel for strength development. It also facilitates a greater degree of 139 geopolymerisation (Diop, Grutzeck \& Molez 2011). 8M NaOH exhibits the optimal concentration 140 for the optimum compressive strength in term of long term performance (Diop et al. 2014). 
143 Different ratios of fly ash/soil were studied $(0,0.3,0.6,0.8$ and 0.9$)$. The ratio of alkali 144 activator/ash was varied in the range of 0.4 to 0.7 and $\mathrm{Na}_{2} \mathrm{SiO}_{3} / \mathrm{NaOH}$ (or $\mathrm{KOH}$ ) $=0.5$, 1 were 145 studied. The residual soil was placed in the oven for it to be dried out for 24 hours at $100{ }^{\circ} \mathrm{C}$. The 146 effect of water content on compressive strength of geopolymer was investigated by adding 147 additional water content (i.e. $10 \%, 20 \%, 30 \%$ and $40 \%$ ) into the mixture. The dry soil was 148 initially premixed with fly ash in a mixer. The alkali activators and additional water content were 149 added into the mixture for further mixing until homogenous state was obtained. The mixture was 150 poured into the modified cube mould $(50 \mathrm{~mm} \times 50 \mathrm{~mm} \times 120 \mathrm{~mm})$ as presented in Fig. 3a. The 151 compression machine was used to press the sample into cubes with dimensions of $50 \mathrm{~mm} \times 50$ $152 \mathrm{~mm} \times 50 \mathrm{~mm}$ (see Fig. 3b) at a press load of $10 \mathrm{kN}$ as shown in Fig. 3c. This press load was fixed 153 at $10 \mathrm{kN}$ due to the limitation of the modified cube mould. The mould might deform if a press load 154 higher than $10 \mathrm{kN}$ was applied. The samples were then demoulded and cured in an oven at different curing temperatures (i.e. $60{ }^{\circ} \mathrm{C}, 100{ }^{\circ} \mathrm{C}$ or $200{ }^{\circ} \mathrm{C}$ ) to investigate the effect of different curing temperatures on compressive strength of geopolymer. Different curing time of the samples was also studied (i.e. dried at room temperature for 2 days then cured in oven for 1 day, direct cured in oven for 1 day and direct cured in oven for 2 days). Table 2 shows the designations of soil-fly ash geopolymers studied in this study. 
163 The mixture was placed into the conical mould on top of the flow table for the workability test

164 immediately after finishing the mixing process. The test was conducted in accordance to ASTM165 C1437 (2013).

166

Compression test

168 Samples were tested for compressive strength after oven curing. The compressive strength of the 169 samples was obtained using compression test machine in accordance to ASTM-C109/C109M 170 (2005).

171

172 Particle Size Distributions

173 The particle size distributions of the fly ash were analysed using the laser particle size analyser

174 (brand: CILAS 1190). However, for the soil, it was obtained using dry sieving and hydrometer test 175 due to its larger particle sizes as compared to the fly ash. The test was performed in accordance to 176 BS-1377-2 (1990).

177

178 Scanning Electron Microscope (SEM)

179 The morphology of the soil-fly ash geopolymer was studied using ZEISS SUPRA 40 VP SEM. A

180 layer of gold was coated on the sample prior to the micrograph analysis. 


\section{Results and discussion}

\section{Effect of additional water content on compressive strength of geopolymer}

184 Fig. 4 shows the effect of additional water content on compressive strength of soil-fly ash geopolymer using different ratios of alkali activator/ash and $\mathrm{Na}_{2} \mathrm{SiO}_{3} / \mathrm{NaOH}(\mathrm{KOH})$. The results show that the reduction of additional water content intensively increases the compressive strength of sample. Samples with the ratio of alkali activator/ash of 0.5 to 0.7 exhibit the highest compressive strength at additional water content of $10 \%$, after which it gradually decreases with the increase of additional water content. It may be due to the reduction of alkalinity in the mixture, which will be discussed here-in-after. Mixture with further increase of additional water appears to be very liquid, particularly at additional water content of $40 \%$. These mixtures were directly cast into the mould with dimensions of $50 \mathrm{~mm} \times 50 \mathrm{~mm} \times 50 \mathrm{~mm}$ as denoted by L in Fig. 4 .

Geopolymer made of alkali activator/ash $=0.4$ shows different trend in strength. The optimum compressive strength was obtained at additional water of 20 to $30 \%$. It is most probably because the mixture at additional water of $10 \%$ is very dry. The sample appeared to be easily broken when minimal load was applied on it. As the additional water increases, it acts as lubricant to improve the formation of rigid structure and hence, it leads to higher strength capability.

The workability of these mixtures is depicted in Fig. 5. It shows similar trend of workability as fly ash-based geopolymer as reported by Leong et al. (2016a). The workability increases when the additional water content and alkali activators increase. From the workability point of view, it may be beneficial to brick making industry using extrusion method. It is important to mention that geopolymer with additional water content of $0 \%$ was unable to produce. It is because that the 
sample at this mixture ratio was very dry and it couldn't form into shape. Hence, the comparison between the sample made with and without additional water content was not available.

Samples made using the press method appear to be more rigid in comparison to those made without using the press method. It is because through pressing the air bubbles/voids within the sample escape into the atmosphere when load is applied to the samples. Hence, entrapped air within the sample is squeezed out from the void spaces thus making the particles closely packed together. It is important to note that the press method is somewhat different from the consolidation process where water content is removed from the sample. Furthermore, the alkali activators within the sample may be further diluted by the excessive additional water content thus reducing the strength capability. The results show that the compressive strength is nearly negligible when the ratio of 216 alkali activator/ash and additional water increase (i.e. when additional water is $40 \%$ and the ratio 217 of alkali activator/ash ranges from 0.4 to 0.7 ). This observation provides a significant insight into the effect of water on compressive strength and the optimum water content for making soil-fly ash geopolymer.

Fig. 6 depicts the morphology images of the soil-fly ash geopolymer at different ratios of additional water content but having same ratios of alkali activators/ash, $\mathrm{Na}_{2} \mathrm{SiO}_{3} / \mathrm{NaOH}$ and fly ash/soil (i.e. SFG11). Geopolymer at these ratios were selected for morphology studies in terms of good compressive strength and the common use of $\mathrm{NaOH}$ and $\mathrm{Na}_{2} \mathrm{SiO}_{3}$ as alkali activators. Fig. 6a shows the SEM image of soil-fly ash geopolymer with additional water content of $10 \%$. The structure was observed to be very dense and rigid. The geopolymer gel was formed surrounding the soil particles, indicating better geopolymerisation. At optimum water content, it reduces the 
distance between soil and fly ash particles. Thus, it leads to higher compressive strength (Sukmak et al. 2013). However, the geopolymer structure became looser and cracks were visible within the samples when the additional water content increased (see Fig. 6b). Layer of alkali activators in excess seems present in the structure as shown in Fig. 6c. It is most probably due to the high water content in the sample, which reduces the contact points amongst fly ash particles and alkali activators for further reaction. At high temperature exposure, the water content within the sample evaporates thus making the alkali activators, which have not used in the geopolymerisation, remain in the structure. Some tiny pores were observed within the sample due to the evaporation of water content. It can be seen that the unreacted fly ash particles were embedded within the sample. This phenomenon is evidently shown in Fig. 6d. The large voids that remained were caused by the unreacted fly ash particles. As the concentration of alkali activator was further reduced by higher additional water content, the formation of geopolymer gel was lesser and therefore more unreacted fly ash particles were presented within the sample. As the bonding of the structure is weaker, these unreacted fly ash particles could be easily broken.

As discussed earlier, the alkalinity of the alkali activator could be reduced by the addition of water subsequently, resulting in reduction of geopolymer strength. The $\mathrm{pOH}$ value increased as the additional water increased subsequently reducing the $\mathrm{pH}$ value. In high $\mathrm{pH}$ environment, the soil particles are expected to be dispersed while the soil particles are flocculated when $\mathrm{pH}$ value is low 247 (Mitchell and Soga 2005). As $\mathrm{NaOH}\left(\right.$ or $\mathrm{KOH}$ ) is categorised as strong base whereas $\mathrm{Na}_{2} \mathrm{SiO}_{3}$ is a 248 weak base, the decrease in strength is governed by the variation of alkalinity in $\mathrm{NaOH}$. Moreover, $249 \mathrm{Na}_{2} \mathrm{SiO}_{3}$ requires dissociation of water to form $\mathrm{OH}^{-}$. The evidence of reduction in $\mathrm{pH}$ values in $250 \mathrm{NaOH}$ as the additional water content increases is shown in Fig. 7. It is noted that the pH values 
are greater than 14 as shown in Fig. 7. Commonly, it is in the range of 1 to 14. It can be attributed to the high initial molarity of alkali activator in this study (i.e. $8 \mathrm{M} \mathrm{NaOH}$ solution). The concentration of $\mathrm{NaOH}$ in the sample also decreases as the water content increases as presented in

Fig. 8. Hence, less fly ash particles are dissolved due to the lower concentration of alkali activators. The decline of geopolymer strength was reported as a result of less geopolymerisation. It is consistent with the observation in Fig. 6 that unreacted fly ash particles increase when the water content increases. The example of evaluation of molarity and $\mathrm{pH}$ value in $\mathrm{NaOH}$ is shown in appendices.

Soil and water particles are not chemically or biologically inert. Other than the absorbed water in soil particles, there are some interactions amongst soil particles, dissolved ions and water molecules. The possible mechanisms that occur between water and soil particles are identified as hydrogen bonding, ion hydration, attraction by osmosis and dipole attraction (Mitchell and Soga 2005). As water molecules have dipolar character, its positive poles are attracted to the negatively charged soil surface particularly in clay particles. The bonds between water molecules and soil particles thus creating an interface layer. It reflects that soil particles are further apart from interacting the fly ash particles or the geopolymer gel formed (due to the reaction amongst fly ash and alkali activators) by the interface layer in close proximity. For the coarser fraction in soil, it has lower specific surface area as compared to the clay particles, causing greater thickness of water layer between soil particles. It indicates that the surface interaction effect is relatively much lower. More water is available and mobilised as the additional water content increases. Therefore, the 272 alkalinity of the alkali activator as mentioned previously could be possibly reduced. It is worth 273 mentioning that soil studied in this study may have positive surface charge. However, the cation 
exchange capability in soil could be much greater than the anion exchange capability due to the high pH environment (Hendershot et al. 2007) in soil-fly ash geopolymer system.

\section{Effect of $\mathrm{Na}_{2} \mathrm{SiO}_{3} / \mathrm{NaOH}(\mathrm{KOH})$ on compressive strength}

The effect of $\mathrm{Na}_{2} \mathrm{SiO}_{3} / \mathrm{NaOH}(\mathrm{KOH})$ on compressive strength of soil-fly ash geopolymer was also studied as shown in Fig. 4. Both $\mathrm{NaOH}-$ and $\mathrm{KOH}-$ based soil-fly ash geopolymer demonstrate the highest compressive strength at the ratios of alkali activator/ash and $\mathrm{Na}_{2} \mathrm{SiO}_{3} / \mathrm{NaOH}$ at 0.6 and 0.5 respectively. The $\mathrm{NaOH}$-based geopolymer exhibits lower compressive strength than the $\mathrm{KOH}-$ based geopolymer. It could be due to more geopolymer precursors that exist in the geopolymer system when $\mathrm{KOH}$ solution is used, hence demonstrating higher strength capability (Xu and Deventer 2000). These results show similar findings as those reported in the previous study when fly ash-based geopolymer was studied (Leong et al. 2016a).

It is suspected that the alkali hydroxide may be more important for strength development than alkali silicate at the optimum additional water content in order to obtain the maximum compressive strength. It is known that alkali hydroxide plays a role of leaching the $\mathrm{Si}$ and $\mathrm{Al}$ content from the reacting fly ash whereas alkali silicate aids in increasing the Si content in the system for geopolymerisation (Xu and Deventer 2000). Sukmak et al. (2013a) reported that partial alkali hydroxide might be absorbed for soil cation exchange and therefore more alkali hydroxide was required than alkali silicate. However, the effect of $\mathrm{Na}_{2} \mathrm{SiO}_{3} / \mathrm{KOH}($ or $\mathrm{NaOH})$ on compressive strength was further investigated as shown in Fig. 9. The results show that the compressive strength increases when $\mathrm{Na}_{2} \mathrm{SiO}_{3} / \mathrm{KOH}$ (or $\mathrm{NaOH}$ ) is increased. However, it decreases with further increase of $\mathrm{Na}_{2} \mathrm{SiO}_{3} / \mathrm{KOH}$ (or $\mathrm{NaOH}$ ). It could be due to an excessive amount of alkali hydroxide within the 
sample as the ratio increases. It may be presented as salt precipitates which hinder the geopolymerisation thus resulting in strength reduction. Hence, it is suggested that an optimum amount of alkali hydroxide and alkali silicate could possibly obtain the maximum compressive strength. This condition is attainable when $\mathrm{Na}_{2} \mathrm{SiO}_{3} / \mathrm{KOH}($ or $\mathrm{NaOH})$ is 0.5 .

\section{Effect of curing condition and curing temperature on compressive strength}

Soil-fly ash geopolymer at the ratios of alkali activator/ash of 0.6 and $\mathrm{Na}_{2} \mathrm{SiO}_{3} / \mathrm{KOH}($ or $\mathrm{NaOH})$ of 0.5 (i.e. the sample exhibits the highest compressive strength) was further studied at different types of curing condition and curing temperature. As shown in Fig. 10, the compressive strength gradually increases as the curing temperature increases with the exception of sample cured directly in oven for 1 day. Diop et al. (2014) explained that the strength gain with the increase of curing temperature was most probably attributed to the dehydroxylation, disintegration and polycondensation of aluminosilicate polymer between the soil particles and alkali activators. In this study, it shows that the loss of moisture increases as the curing temperature increases. It is thought that the sample which was initially dried at room temperature for 2 days could aid in removing the water content within the sample thus enhancing the geopolymerisation between fly ash and alkali activators subsequently leading to higher compressive strength. However, on the contrary, the moisture loss at this type of curing condition shows similarity to the other types of

315 curing condition. It shows that room temperature curing only aids in removing the moisture on 316 sample surface. For moisture within the sample, it requires oven heating and thus it explains 317 moisture loss due to oven curing is similar. 
Comparing the geopolymer samples cured in oven for 1 day and 2 days, strength gain over longer curing duration was observed in sample cured at $60{ }^{\circ} \mathrm{C}$ only. It is most likely due to the increase of moisture loss. Samples cured at low temperature might need longer duration of oven curing to build up the strength (Sukmak et al. 2013b). However, having the same curing duration at $100^{\circ} \mathrm{C}$ and $200^{\circ} \mathrm{C}$, strength reduction was observed. It could be due to high temperature exposure and more cracks develop in the sample. The loss of moisture from 1-day oven curing to 2-day oven curing is minimal. This implies that most of the moisture had been evaporated within first 24 hours.

It also demonstrated that longer duration of oven curing does not necessarily lead to higher compressive strength but resulting in strength reduction in particular to the sample cured at high temperature.

The highest compressive strength is obtained when the samples were cured directly in oven for 1 day. It intensively increased from $60^{\circ} \mathrm{C}$ to $100^{\circ} \mathrm{C}$ and decreased from $100^{\circ} \mathrm{C}$ to $200^{\circ} \mathrm{C}$. This suggested that sample cured in oven plays an important role in strength development for soil-fly ash geopolymer. Additionally, it is postulated that sample cured at this type of curing condition

334 (i.e. directly cured in oven for 1 day at $100^{\circ} \mathrm{C}$ ) achieved the initial maximum strength. As 335 mentioned earlier, moisture within the sample might not able to evaporate at low curing 336 temperature. High temperature exposure may result in crack development subsequently reducing 337 the strength capabilities. An adequate curing temperature (i.e. $100{ }^{\circ} \mathrm{C}$ in this case) facilitates the 338 moisture evaporation and geopolymerisation for forming a rigid structure within first 24 hours. 339 Therefore, this condition may be adequate for making soil-fly ash geopolymer as it required short 340 curing duration, moderate curing temperature but it exhibits the highest strength capability. 
342 Fig. 11a-c presents the morphologies of the geopolymer samples cured directly in oven for 1 day 343 at different curing temperatures. At $60^{\circ} \mathrm{C}$, agglomeration of particles was observed. The 344 geopolymer structure appeared to be non-homogenous and consisted coagulation of fly ash 345 particles and alkali activators around the soil particles. The geopolymer gel formed was distributed 346 in scatter within the sample. Moreover, some unreacted or partially dissolved fly ash particles were 347 also present as marked in the figure. This observation shows that the geopolymerisation process is 348 incomplete. The geopolymer sample depicted in Fig. 11b exhibits more homogenity and a more 349 compact microstructure. Furthermore, the phenomenon described in Fig. 11a did not occur. It 350 implied that geopolymer cured at $100^{\circ} \mathrm{C}$ enhances the geopolymerisation for soil-fly ash 351 geopolymer. When the curing temperature increases to $200^{\circ} \mathrm{C}$, different structure was observed as 352 illustrated in Fig. 11c. The soil particles and geopolymer gel seem to have fused together due to 353 high temperature exposure. However, the sample showed less dense structure and cracks occurred 354 as marked. Evaporation of the water content at high temperature increased the porosity within the sample thus causing the strength to decrease.

\section{Effect of fly ash/soil on compressive strength}

358 The effect of the ratio of fly ash/soil on compressive strength was studied and illustrated in Fig.

359 12. The compressive strength gradually increased when the ratio of fly ash/soil increased. It is 360 most likely due to the increase of fly ash content, which enhances the geopolymerisation within 361 the sample. It is evident that the geopolymer strength increased as the amount of alkali activators 362 increased regardless of the types of alkali activator. The amorphous phase of $\mathrm{SiO}_{2}$ and $\mathrm{Al}_{2} \mathrm{O}_{3}$ 363 contents could be leached out from the fly ash. Hence, more geopolymer could be sufficiently 364 formed to bind the soil particles together thus increasing the compressive strength. Although soil 
contains high $\mathrm{SiO}_{2}$ and $\mathrm{Al}_{2} \mathrm{O}_{3}$ contents, it is mostly presented in the crystalline phase (Phetchuay et al. 2014). It acts as fine aggregate (Sukmak et al. 2013a) and contribution to the formation of geopolymer gel is unlikely. It is also noted that $\mathrm{Na}_{2} \mathrm{SiO}_{3}$ content is lower than $\mathrm{NaOH}$ content in geopolymer. As reported in previous study, $\mathrm{Na}_{2} \mathrm{SiO}_{3}$ provides more $\mathrm{Si}$ content to the geopolymer system whereas $\mathrm{NaOH}$ dissolves alumina and silica from the fly ash particles (Leong et al. 2016a). However, increase of $\mathrm{Na}_{2} \mathrm{SiO}_{3}$ may obstruct $\mathrm{NaOH}$ to dissolve the essential elements for geopolymerisation. Hence, an adequate amount of $\mathrm{Na}_{2} \mathrm{SiO}_{3}$ and $\mathrm{NaOH}$ should be adopted for good strength result. The SEM images in Fig. 13 show that more geopolymer gel was formed as the ratio of fly ash/soil increased. The strength results obtained in this study had shown well agreement to the microscopy observations.

More unreacted fly ash particles were observed at low ratio of fly ash/soil. The structure of the sample becomes more rigid and less undissolved fly ash particles were observed as the ratio of fly ash/soil increased. Samples made using 100\% fly ash exhibited the most homogenous structure, however, cracks were obviously seen in the sample due to high temperature exposure. Fly ash particles were mostly unreacted in samples cured at room temperature regardless of the ratio of fly ash/soil as shown in Fig. 14. Moreover, no obvious changes of the microstructure were observed over the increase of the ratio of fly ash/soil. This observation was in agreement to the strength results and it explained the reason behind the insignificant strength gain. Although low 384 compressive strength was obtained in samples cured at room temperature, the SEM images proved 385 that geopolymer gel could be formed at room temperature. However, it might require longer 386 duration to achieve the desired strength. 
The strength results of the samples made using $100 \%$ soil and $100 \%$ fly ash demonstrated that the trend of the strength development in terms of the ratio of fly ash/soil is principally caused by the geopolymerisation. Sample made using 100\% soil exhibited very low compressive strength when curing at room temperature. As no aluminosilicate gel was formed, it showed good evidences that the geopolymerisation gel could effectively increase the geopolymer strength when fly ash and alkali activators were added into the soil. The latter type of curing condition also showed that the strength gained (i.e. $0.18 \mathrm{MPa}$ ) was mainly due to the press method at $10 \mathrm{kN}$. Hence, the remaining strength is built up through the temperature exposure and geopolymerisation. Therefore, strength gained due to these two factors can be evaluated by data presented in Fig. 15. The results showed that the increase of compressive strength due to the geopolymerisation at room temperature was minimal as compared to the geopolymerisation at temperature exposure. This results show well agreement to the findings obtained in fly ash-based geopolymer as reported by Leong et al. (2016a). These observations showed that soil-fly ash geopolymer behaved similar geopolymerisation as in fly ash-based geopolymer. Curing temperature plays an important role in strength development regardless of the types of raw material.

In Fig. 12 and Fig. 15, the mixing sequence of raw materials were investigated and denoted as M1 and M2. M1 represents the sample premixed with soil and fly ash prior to the addition of liquid content whereas M2 represents premixing fly ash with the liquid content followed by the addition of soil. It is thought that the formation of aluminosilicate gel in M2 could effectively bind the soil particles thus leading to higher strength capability. However, the results reflected that samples prepared from M1 obtain higher strength gain than sample prepared from M2 as tabulated in Table 
412 It is postulated that the fly ash particles are packed closely between the soil particles during the 413 premixing process in M1 as the former particles show much smaller particle sizes as compared to

414 the latter as evidenced in Fig. 2. When alkali activators were added into the mixture, it dissolved

415 the fly ash particles surrounding the soil particles. Hence, the aluminosilicate gel was formed 416 around the soil particles. Moreover, the negatively charged surface of soil particle held some of 417 the cations from the alkali activators, resulting in high concentration of absorbed cations near the 418 surface of soil particles. It implied that the anions such as $\mathrm{OH}^{-}$and $\mathrm{SiO}_{3}{ }^{2-}$ from the alkali activators 419 are adjacent to the fly ash particles, which are the essential ions for dissolution of fly ash particles 420 and the geopolymerisation process. Combining these two factors, a strong interaction and reaction 421 amongst soil particles, fly ash particles and alkali activators are developed, forming a rigid 422 structure for better strength capability.

424 For samples prepared from M2, the formation of aluminosilicate gel due the reaction of fly ash particles and alkali activators may not sufficient to bind the soil particles completely. In this case, the binding effect only occurred in limited region of the sample. Therefore, the structure formed may not be as rigid and homogenous as achieved in M1.

429 Conclusion

430 The effect of the ratio of fly ash/soil, the ratio of alkali activator/ash, the ratio of $\mathrm{Na}_{2} \mathrm{SiO}_{3} / \mathrm{KOH}$ (or $\mathrm{NaOH}$ ), additional water content, curing condition and curing temperature on compressive strength of soil-fly ash geopolymer had been successfully studied. The following conclusions can be made: 
434 1. Soil-fly ash geopolymer obtains the highest compressive strength when the ratio of alkali activator/ash of 0.6 , the ratio of $\mathrm{Na}_{2} \mathrm{SiO}_{3} / \mathrm{KOH}($ or $\mathrm{NaOH})$ of 0.5 and additional water of $10 \%$.

436 The effect of additional water on compressive strength shows similar pattern regardless of the $437 \quad$ types of alkali activators.

2. Water is essential in shaping and forming soil-fly ash geopolymer. However, excessive water and alkali activators were not suitable for press method although it shows high workability. The increase in additional water content decreases the alkalinity and molarity of alkali activator, causing the geopolymer strength to decline.

3. More alkali activators are required for soil-fly ash geopolymer to obtain maximum compressive strength as compared to fly ash-based geopolymer. It organic matter in soil may behave as absorbent for alkali activators.

4. The compressive strength increases when the curing temperature increases. However, high curing temperature and long curing duration do not lead to higher compressive strength. Loss of moisture was reported during the curing process. Sample directly cured in oven for 1 day at $100{ }^{\circ} \mathrm{C}$ exhibits the highest compressive strength.

5. The compressive strength increases as the ratio of fly ash/soil increases. The increase of fly ash content is associated with more alkali activators that increases the formation of geopolymerisation gel thus resulting in binding of the soil particles.

6. Different mixing sequences of the raw materials used were also studied. Premixed fly ash and soil before adding the liquid contents shows better formation of geopolymer gel within the sample, thus resulting more significant strength capability. 
7. In this study, the compressive strength of soil-fly ash geopolymer ranges from $0.88 \mathrm{MPa}$ to 32.05 MPa. It is thus evidenced that fly ash and residual soil can be potentially used to produce soil-fly ash geopolymer, an alternative to traditional clay fired brick.

\section{Acknowledgement}

The first author would like to acknowledge the financial support from Swinburne Sarawak Research Centre for Sustainable Technologies for supporting her travel to Melbourne to conduct the experiments. The authors would like to acknowledge the advice and assistance rendered by Dr Ng Sing Muk, Dr James Wang, Dr Kueh Sze Miang, Lionel Foo Fang Ho, Liew Lik Giin, Vincent Ho, Bartholomew Woodham, Department of Agriculture and Water Resources (Australia), Ceramic Indah Sdn Bhd (Kim Hin), Jung Kuo Sdn Bhd and Jembina (East Malaysia) Sdn Bhd.

\section{Appendices}

\section{Evaluation of molarity and $\mathrm{pH}$ value in $\mathrm{NaOH}$}

$\mathrm{NaOH}<->\mathrm{Na}^{+}+\mathrm{OH}^{-}$

Assume: $\quad 8 \mathrm{M} \mathrm{NaOH}=106.7 \mathrm{~g}$

$$
\text { Water }=50 \mathrm{~g}
$$

Consider $1 \mathrm{~g} / \mathrm{mL}$,

Molarity, $\mathrm{M}_{\mathrm{NaOH}(8 \mathrm{M})}=106.7 \mathrm{~g}$

$$
\text { Volume, } \mathrm{V}_{\mathrm{NaOH}(8 \mathrm{M})}=106.7 \mathrm{~mL}
$$

Number of mol, $\mathrm{n}_{\mathrm{NaOH}}=\left(106.7 \mathrm{~mL} \times 10^{-3}\right) \times 8 \mathrm{M}$

$$
=0.853 \mathrm{~mol}
$$

Volume of solution $=(106.7+50) \times 10^{-3}$ 
Molarity of $O H^{-}=\frac{0.853 \mathrm{~mol}}{0.157 \mathrm{~L}}$

$\mathrm{p}\left(O H^{-}\right)=-\log _{10}\left(\mathrm{OH}^{-}\right)$

$\mathrm{pH}=14-(-0.74)$

\section{References}

ASTM-C109/C109M (2005). "Standard Test Method for Compressive Strength of Hydraulic Cement Mortars (Using 2-in. or [50-mm] Cube Specimens)." ASTM International.

ASTM-C618 (2005). "Standard Specification for Coal Fly Ash and Raw or Calcined Natural Pozzolan for Use in Concrete."

ASTM-C1437 (2013). "Standard Test Method for Flow of Hydraulic Cement Mortar."ASTM International.

Bories, C., Aouba, L., Vedrenne, E., and Vilarem, G. (2015). "Fired clay bricks using agricultural biomass wastes: Study and characterization." Constr. Build. Mater., 91, 158-163.

BS-1377-2 (1990). "Methods of test for soils for civil engineering purposes: Classification tests."

Casa, J. A. d. 1., and Castro, E. (2014). "Recycling of washed olive pomace ash for fired clay brick manufacturing." Constr. Build. Mater., 61, 320-326.

Criado, M., Fernández-Jiménez, A., Torre, A. G. d. 1., Aranda, M. A. G., and Palomo, A. (2007). "An XRD study of the effect of the $\mathrm{SiO} 2 / \mathrm{Na} 2 \mathrm{O}$ ratio on the alkali activation of fly ash." Cem. Con. Res., 37 671-679.

Cristelo, N., Glendinning, S., Fernandes, L., and Pinto, A. n. T. (2013). "Effects of alkalineactivated fly ash and Portland cement on soft soil stabilisation." Acta Geotechnica (2013) $8: 395-405$.

Cristelo, N., Glendinning, S., Miranda, T., Oliveira, D., and Silva, R. (2012). "Soil stabilisation using alkaline activation of fly ash for self compacting rammed earth construction." Construction and Building Materials 36 (2012) 727-735.

Davidovits, J. (2008). Geopolymer Chemistry and Application Institute Geopolymer France.

Diop, M. B., Grutzeck, M. W., and Molez, L. (2011). "Comparing the performances of bricks made with natural clay and clay activated by calcination and addition of sodium silicate." Applied Clay Science 54, 172-178. 
Diop, M. B., Molez, L., Bouguerra, A., Diouf, A. N., and Grutzeck, M. W. (2014). "Manufacturing Brick from Attapulgite Clay at Low Temperature by Geopolymerization." Arab J Sci Eng 39, 4351-4361.

Duxson, P., Provis, J. L., Lukey, G. C., and Deventer, J. S. J. v. (2007). "The role of inorganic polymer technology in the development of 'green concrete'." Cem. Con. Res., 37, 15901597.

Hardjito, D., and Rangan, B. V. (2005). "Development and Properties of Low-Calcium Fly Ashbased Geopolymer Concrete." Curtin University of Technology, Perth, Australia 48.

Heah, C. Y., Kamarudin, H., Bakri, A. M. M. A., Bnhussain, M., Luqman, M., Nizar, I. K., Ruzaidi, C. M., and Liew, Y. M. (2012). "Study on solids-to-liquid and alkaline activator ratios on kaolin-based geopolymers." Constr. Build. Mater., 35, 912-922.

Hendershot, W. H., Lalande, H., and Duquette, M. (2007). "Ion Exchange and Exchangeable Cations." Soil Sampling and Methods of Analysis, M. R. Carter, and E. G. Gregorich, eds., Canadian Society of Soil Science, FL, 197-206.

Komljenovi, M., Bascarevi, Z., and Bradic, V. (2010). "Mechanical and microstructural properties of alkali-activated fly ash geopolymers." J. Hazard. Mater., 181, 35-42.

Leong, H. Y., Ong, D. E. L., Sanjayan, J. G., and Nazari, A. (2015). "A genetic programming predictive model for parametric study on factors affecting strength of geopolymers " RSC Adv., 5, 85630-85639.

Leong, H. Y., Ong, D. E. L., Sanjayan, J. G., and Nazari, A. (2016a). "The effect of different Na2O and $\mathrm{K} 2 \mathrm{O}$ ratios of alkali activator on compressive strength of fly ash based-geopolymer." Constr. Build. Mater., 106, 500-511.

Leong, H. Y., Ong, D. E. L., Sanjayan, J. G., and Nazari, A. (2016b). "Sustainability of Sarawak and Gladstone fly ash to produce geopolymers: A physical, chemical, mechanical, mineralogical and microstructural analysis." Ceram. Int., 42, 9613-9620.

Lingling, X., Wei, G., Tao, W., and Nanru, Y. (2005). "Study on fired bricks with replacing clay by fly ash in high volume ratio." Constr. Build. Mater., 19, 243-247.

Mitchell, J. K., and Soga, K. (2005). "Fundamentals of Soil Behavior." John Wiley \& Sons, Inc, Canada.

Nematollahi, B., and Sanjayan, J. (2014). "Effect of different superplasticizers and activator combinations on workability and strength of fly ash based geopolymer." Mater. Design, 57, 667-672.

Ogundiran, M. B., and Kumar, S. (2015). "Synthesis and characterisation of geopolymer from Nigerian Clay." Applied Clay Science 108, 173-181.

Phetchuay, C., Horpibulsuk, S., Arulrajah, A., Suksiripattanapong, C., and Udomchai, A. (2016). "Strength development in soft marine clay stabilized by fly ash and calcium carbide residue based geopolymer." Applied Clay Science 127-128, 134-142.

Phetchuay, C., Horpibulsuk, S., Suksiripattanapong, C., Chinkulkijniwat, A., Arulrajah, A., and Disfani, M. M. (2014). "Calcium carbide residue: Alkaline activator for clay-fly ash geopolymer." Constr. Build. Mater., 69, 285-294.

Phummiphan, I., Horpibulsuk, S., Sukmak, P., Chinkulkijniwat, A., Arulrajah, A., and Shen, S.-L. (2016a). "Stabilisation of marginal lateritic soil using high calcium fly ash-based geopolymer." Road Materials and Pavement Design, 17(4), 877-891.

Phummiphan, I., Horpibulsuk, S., Phoo-ngernkham, T., Arulrajah, A., and Shen, S.-L. (2016b) "Marginal Lateritic Soil Stabilized with Calcium Carbide Residue and Fly Ash 
Geopolymers as a Sustainable Pavement Base Material." J. Mater. Civ. Eng., 04016195(04016110).

Power Pile (2013). "What is Expanding PowerPile Geopolymer Pillar?" PowerPile Pillars, $<$ http://powerpile.com/what-is-powerpile-expanding-polymer-pillar $>$.

Ryu, G. S., Lee, Y. B., Koh, K. T., and Chung, Y. S. (2013). "The mechanical properties of fly ash-based geopolymer concrete with alkaline activators." Constr. Build. Mater., 47, 409418.

Sarker, P. K. (2008). "Analysis of geopolymer concrete columns." Materials and Structures (2009) 42:715-724.

Shrest, P. (2013). "Development of Geopolymer Concrete for Precast Structures." The University of Texas, Arlington.

Sukmak, P., Horpibulsuk, S., and Shen, S.-L. (2013a). "Strength development in clay-fly ash geopolymer." Constr. Build. Mater., 40, 566-574.

Sukmak, P., Horpibulsuk, S., Shen, S.-L., Chindaprasirt, P., and Suksiripattanapong, C. (2013b). "Factors influencing strength development in clay-fly ash geopolymer." Constr. Build. Mater., 47, 1125-1136.

Tennakoon, C., Nazari, A., Sanjayan, J. G., and Sagoe-Crentsil, K. (2014). "Distribution of oxides in fly ash controls strength evolution of geopolymers." Constr. Build. Mater., 71, 72-82.

Uretek (2014). "Deep Injection." Methods, $<$ http://www.uretekworldwide.com/solutions/methods/geopolymer-injection>.

Velasco, P. M., Ortíz, M. P. M., Giró, M. A. M., and Velasco, L. M. (2014). "Fired clay bricks manufactured by adding wastes as sustainable construction material - A review." Constr. Build. Mater., 63, 97-107.

Wesley, L. D. (2010). Fundamentals of Soil Mechanics for Sedimentary and Residual Soils, John Wiley \& Sons, Inc, Canada.

Xu, H., and Deventer, J. S. J. V. (2000). "The geopolymerisation of alumino-silicate minerals." Int. J. Miner. Process., 59, 247-266.

Xu, L., Guo, W., Wang, T., and Yang, N. (2005). "Study on fired bricks with replacing clay by fly ash in high volume ratio." Constr. Build. Mater., 19, 243-247.

Zhang, L. (2013). "Production of bricks from waste materials - A review." Constr. Build. Mater., 47, 643-655.

Zhang, M., Guo, H., El-Korchi, T., Zhang, G., and Tao, M. (2013). "Experimental feasibility study of geopolymer as the next-generation soil stabilizer." Construction and Building Materials 47 (2013) 1468-1478.

Zhang, Z., Qian, J., You, C., and Hu, C. (2012). "Use of circulating fluidized bed combustion fly ash and slag in autoclaved brick." Constr. Build. Mater., 35, 109-116. 
Table 1. Chemical Composition of Fly Ash and Residual Soil

\begin{tabular}{ccc}
\hline Elements (\%) & Sarawak Fly Ash & Residual Soil \\
\hline $\mathrm{SiO}_{2}$ & 43.8 & 32.71 \\
\hline $\mathrm{Al}_{2} \mathrm{O}_{3}$ & 18.1 & 25.33 \\
\hline $\mathrm{Fe}_{2} \mathrm{O}_{3}$ & 7.7 & 21.29 \\
\hline $\mathrm{CaO}$ & 3.9 & 0.04 \\
\hline $\mathrm{MgO}$ & 0.5 & 0.22 \\
\hline $\mathrm{MnO}$ & 22.8 & - \\
\hline $\mathrm{K}_{2} \mathrm{O}$ & 2.0 & 0.03 \\
\hline $\mathrm{Na}_{2} \mathrm{O}$ & 0.3 & 0.07 \\
\hline $\mathrm{SO}_{3}$ & 0.1 & 0.01 \\
\hline $\mathrm{TiO}_{2}$ & 0.6 & - \\
\hline $\mathrm{P}_{2} \mathrm{O}_{5}$ & 0.1 & - \\
\hline $\mathrm{LOI}$ & 0.5 & 17.18 \\
\hline
\end{tabular}

605

606

607

608

609

610

611

612

613

614

615

616

617

618

619

620

621

622

623

624

625 


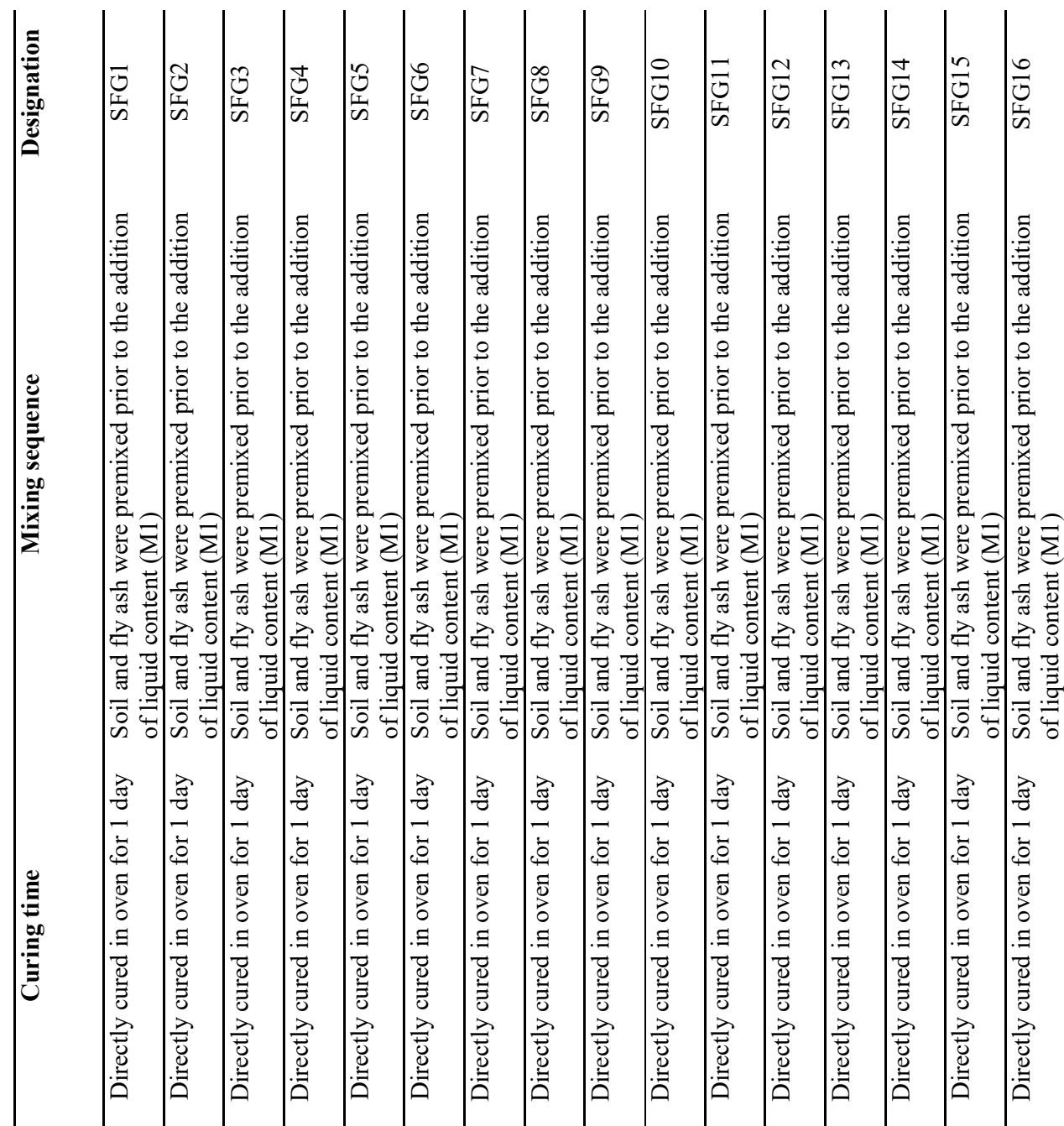

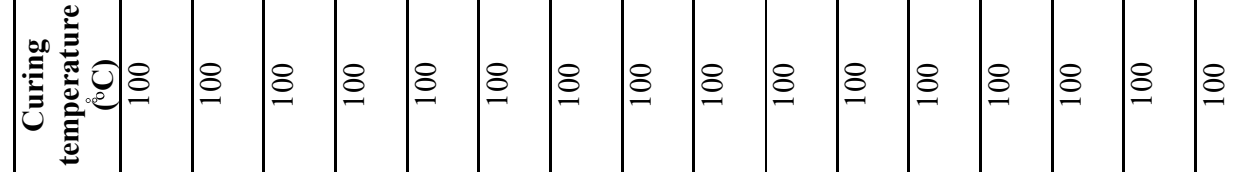

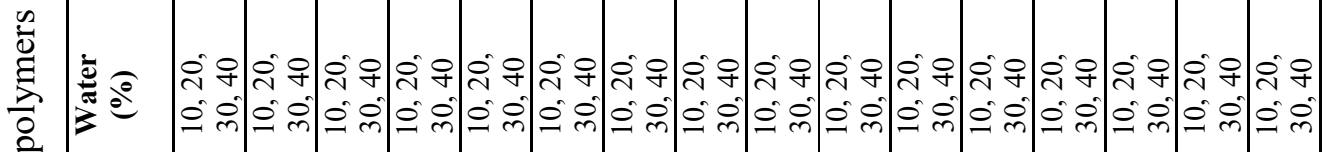

¿

氶

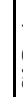

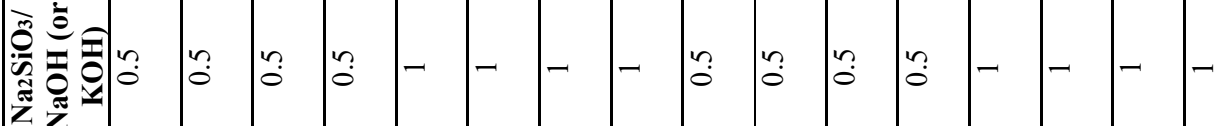

$\frac{1}{8}$

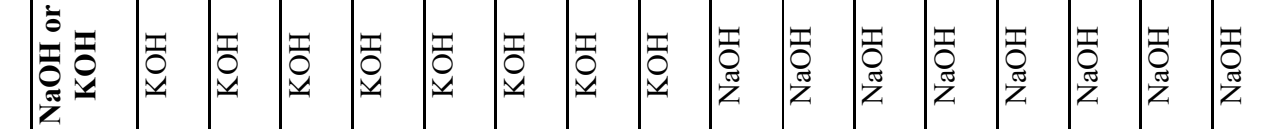

.

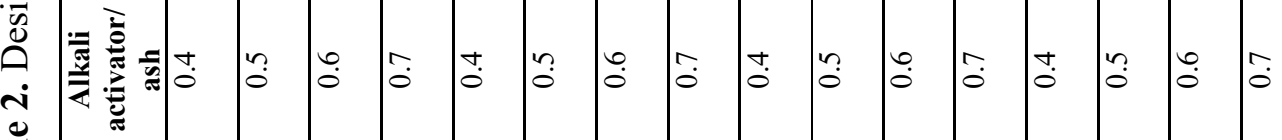

产

กัర

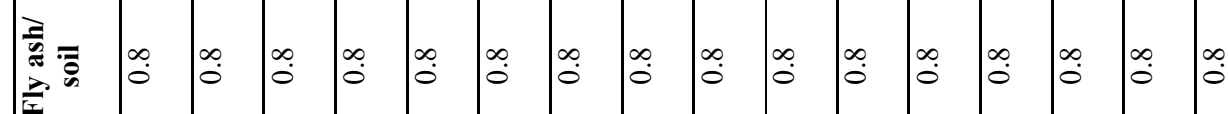

స్తి क్ శ్ శ్ 


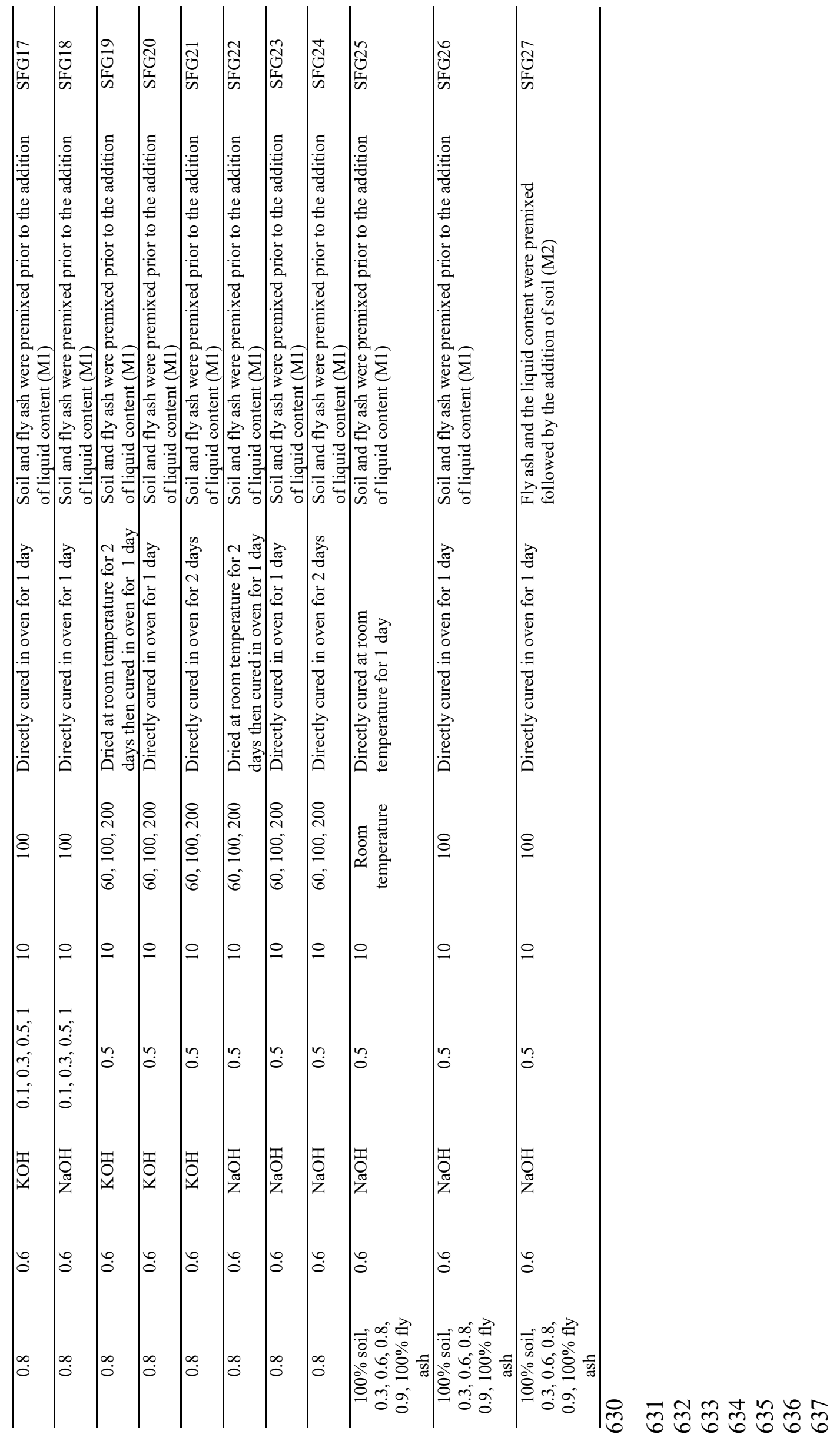


638 Table 3. Strength increment due to sequence of mixing

\begin{tabular}{ccc}
\hline Ratio of fly ash/soil & M1 (\%) & M2 (\%) \\
\hline $\mathbf{0 . 3}$ & 45.08 & 66.95 \\
\hline $\mathbf{0 . 6}$ & 86.22 & 78.25 \\
\hline $\mathbf{0 . 8}$ & 92.30 & 80.29 \\
\hline $\mathbf{0 . 9}$ & 90.81 & 77.53 \\
\hline
\end{tabular}

639

640

641

642

643

644

645

646

647

648

649 
Table 1. Chemical Composition of Fly Ash and Residual Soil

\begin{tabular}{|c|c|c|}
\hline Elements (\%) & Sarawak Fly Ash & Residual Soil \\
\hline $\mathrm{SiO}_{2}$ & 43.8 & 32.71 \\
\hline $\mathrm{Al}_{2} \mathrm{O}_{3}$ & 18.1 & 25.33 \\
\hline $\mathrm{Fe}_{2} \mathrm{O}_{3}$ & 7.7 & 21.29 \\
\hline $\mathrm{CaO}$ & 3.9 & 0.04 \\
\hline $\mathrm{MgO}$ & 0.5 & 0.22 \\
\hline $\mathrm{MnO}$ & 22.8 & - \\
\hline $\mathrm{K}_{2} \mathrm{O}$ & 2.0 & 0.03 \\
\hline $\mathrm{Na}_{2} \mathrm{O}$ & 0.3 & 0.07 \\
\hline $\mathrm{SO}_{3}$ & 0.1 & 0.01 \\
\hline $\mathrm{TiO}_{2}$ & 0.6 & - \\
\hline $\mathrm{P}_{2} \mathrm{O}_{5}$ & 0.1 & - \\
\hline LOI & 0.5 & 17.18 \\
\hline
\end{tabular}




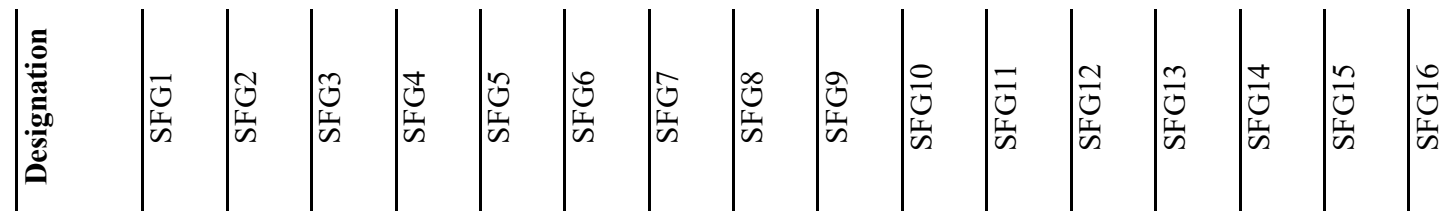

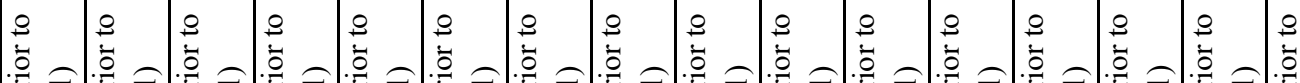

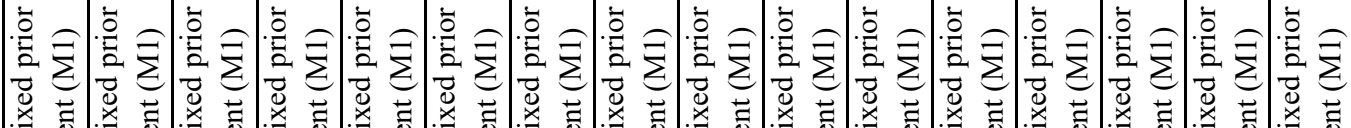

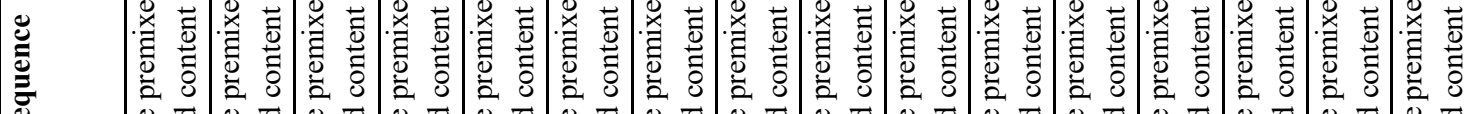

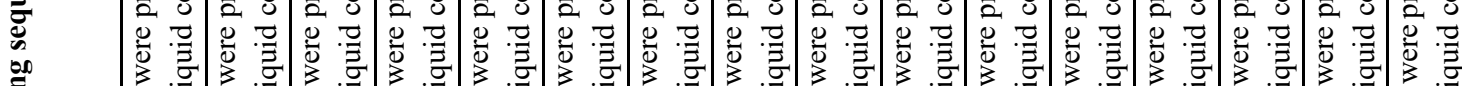

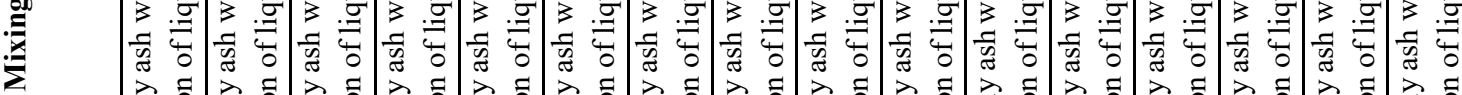

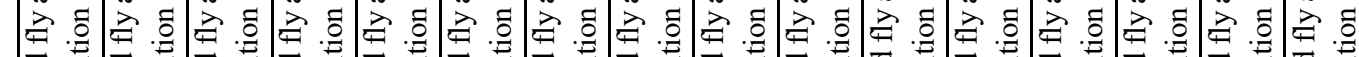

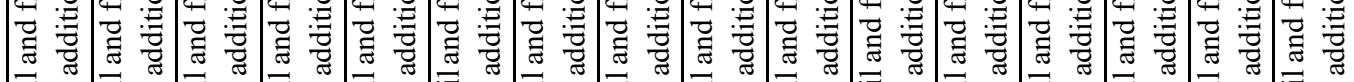

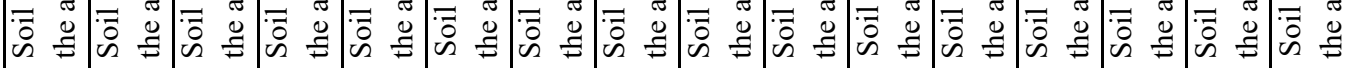

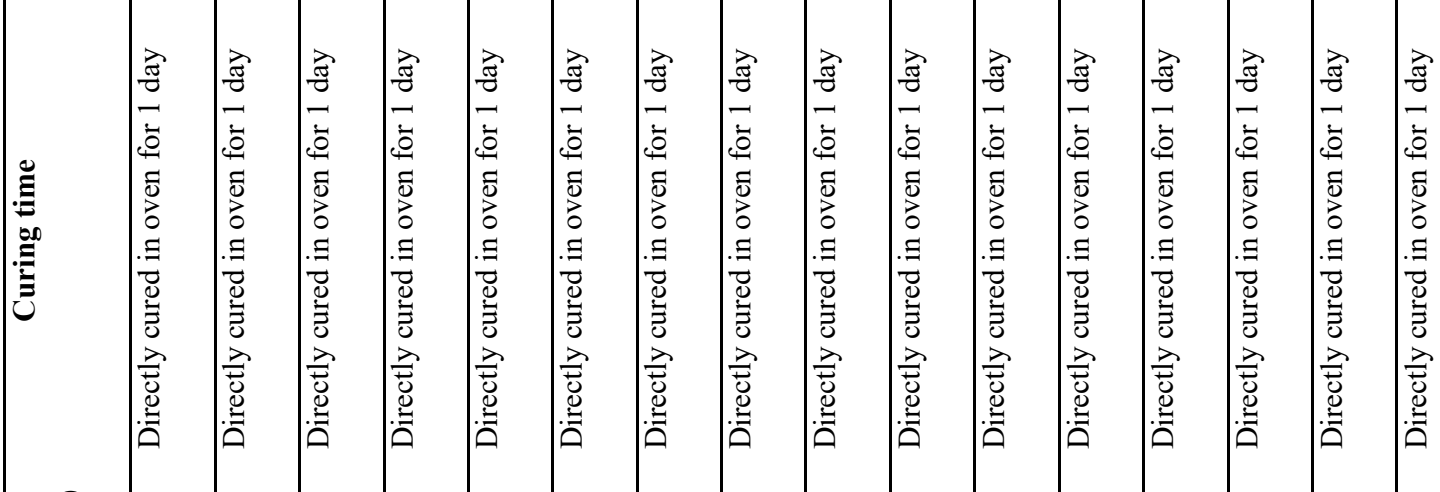

\&

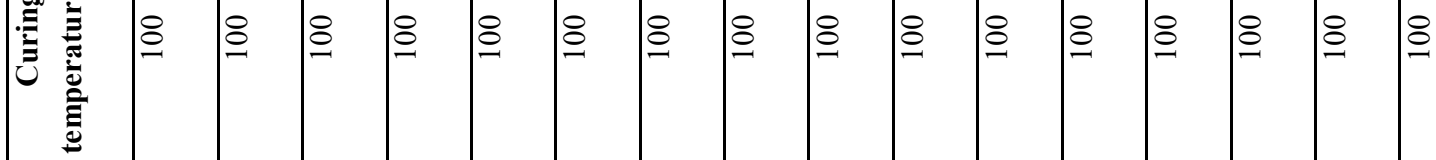

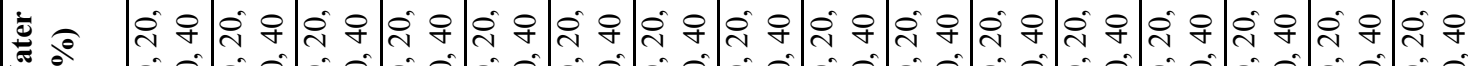

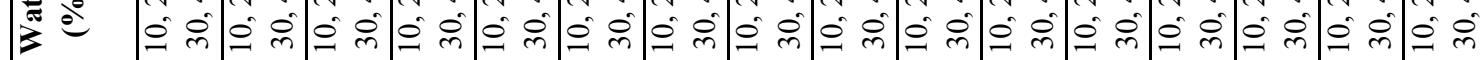

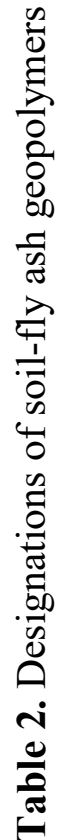

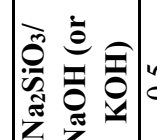

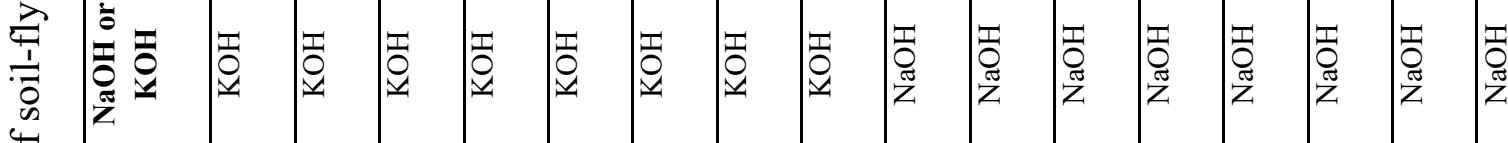

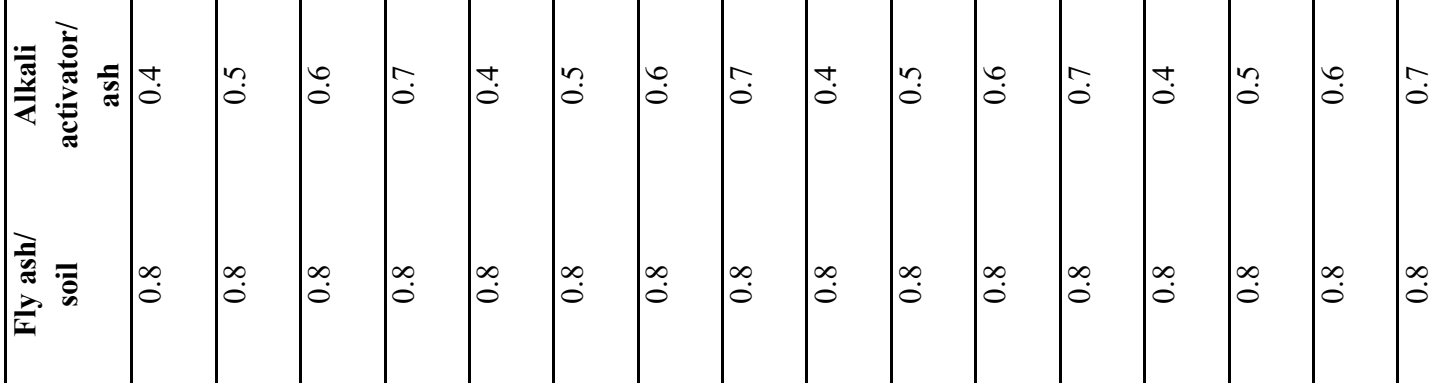




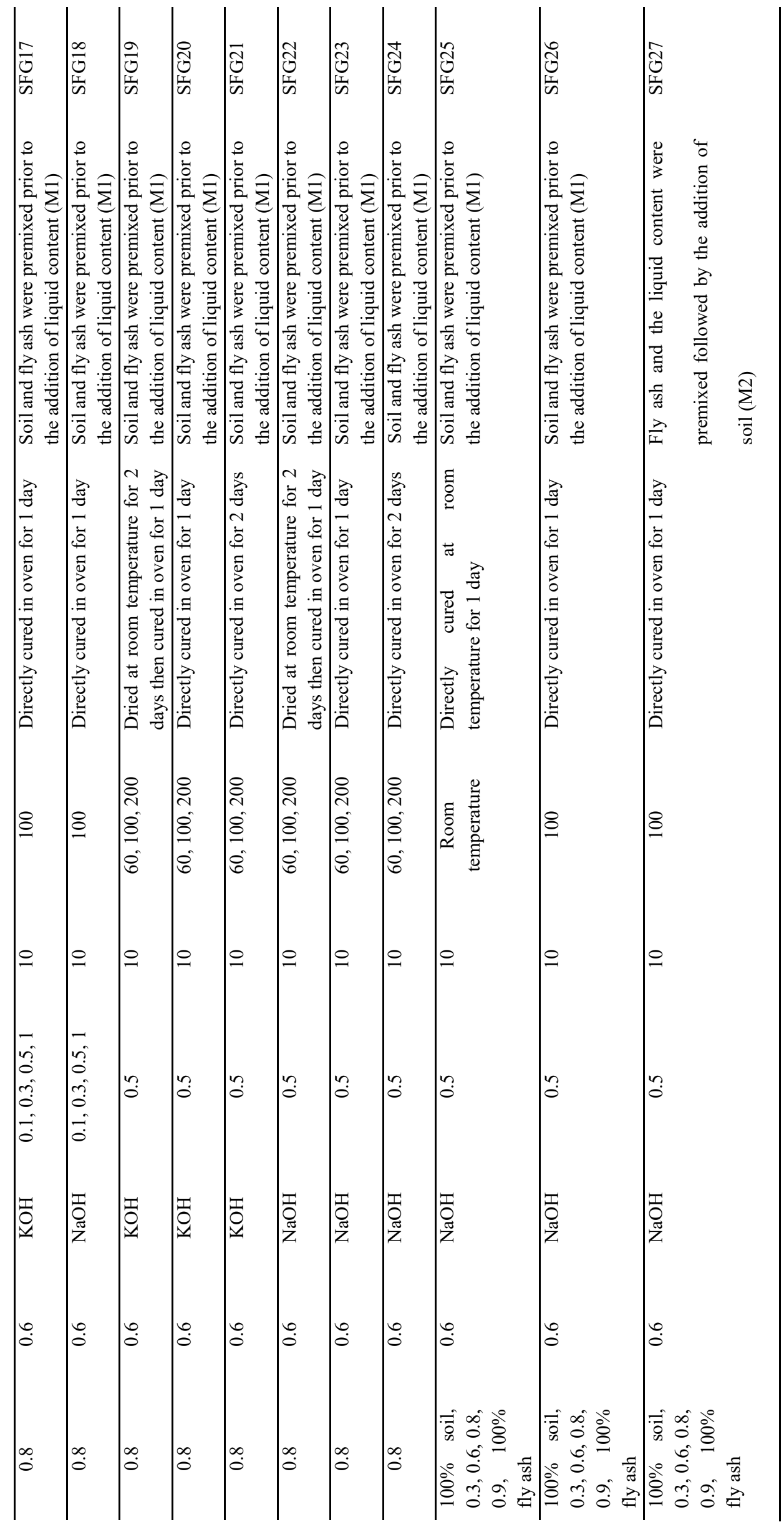


Table 3. Strength increment due to sequence of mixing

\begin{tabular}{ccc}
\hline $\begin{array}{c}\text { Ratio of fly } \\
\text { ash/soil }\end{array}$ & M1 (\%) & M2 (\%) \\
\hline $\mathbf{0 . 3}$ & 45.08 & 66.95 \\
$\mathbf{0 . 6}$ & 86.22 & 78.25 \\
$\mathbf{0 . 8}$ & 92.30 & 80.29 \\
$\mathbf{0 . 9}$ & 90.81 & 77.53 \\
\hline
\end{tabular}




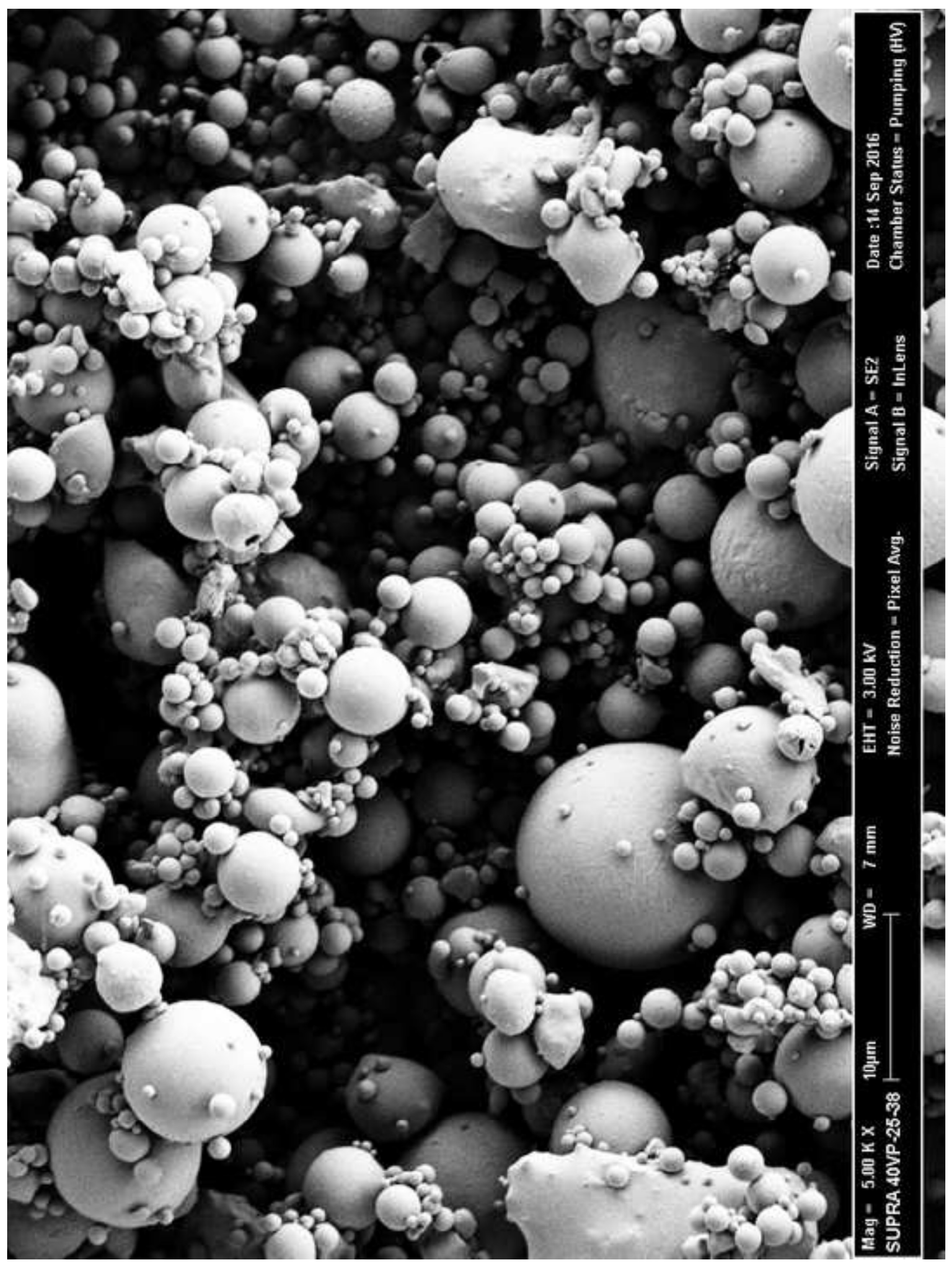




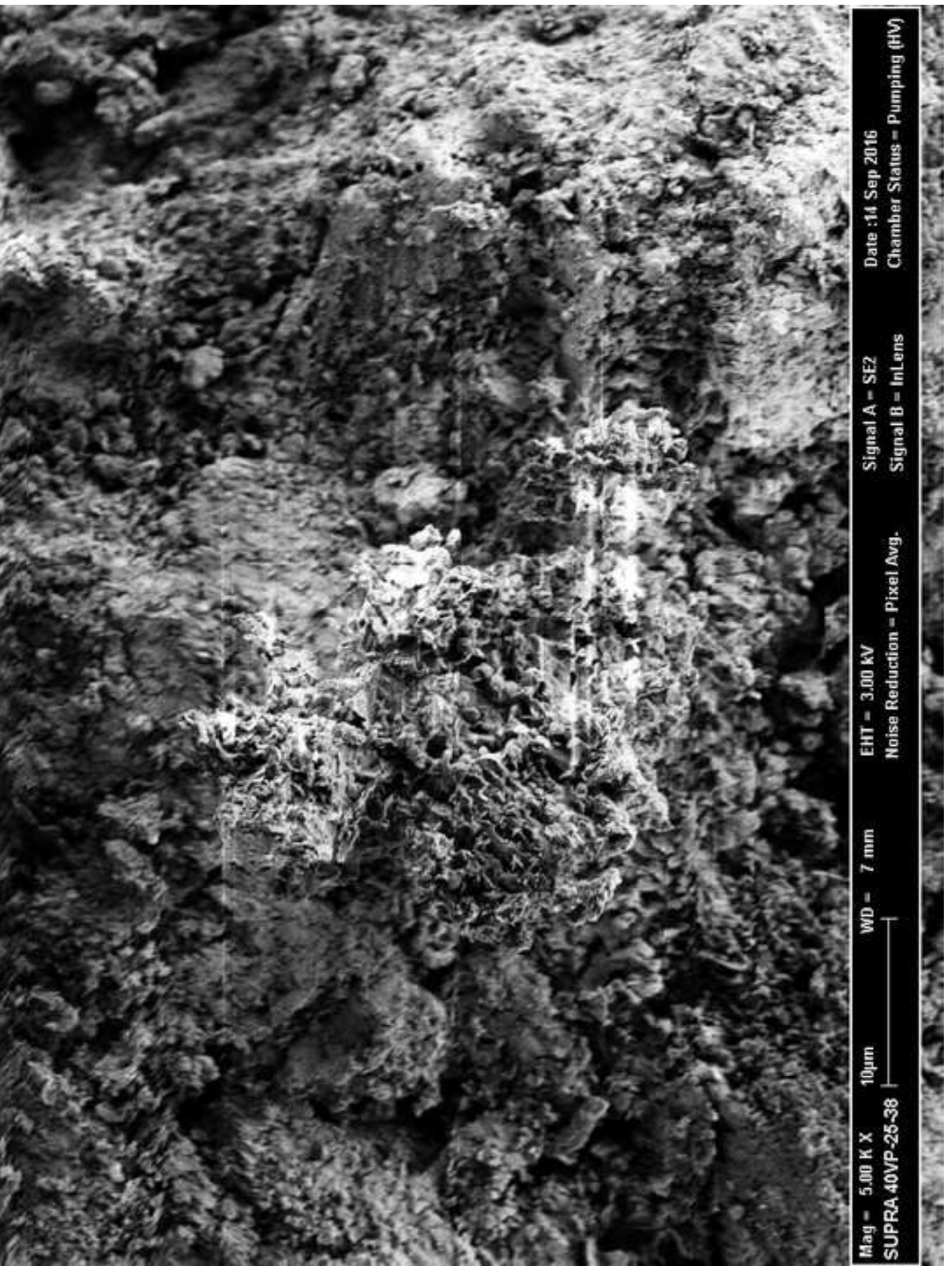




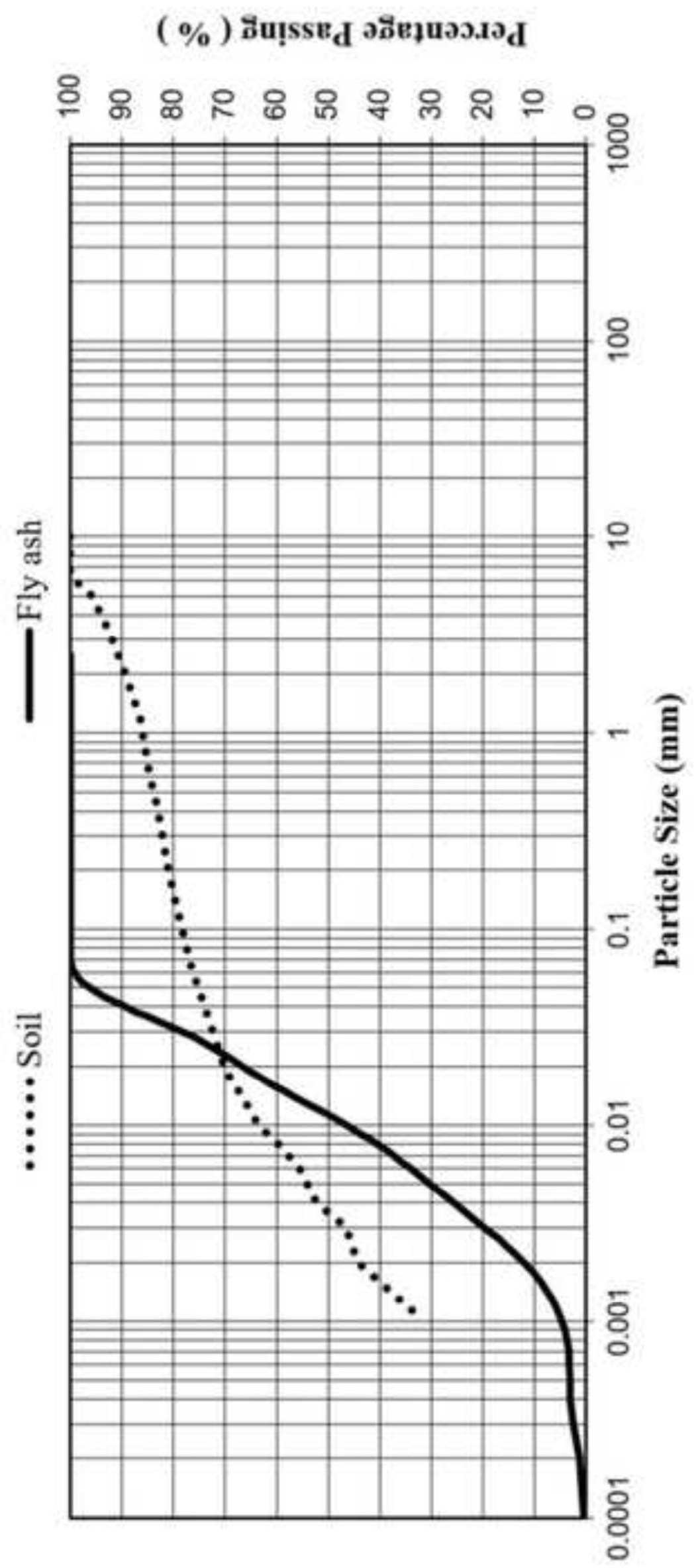




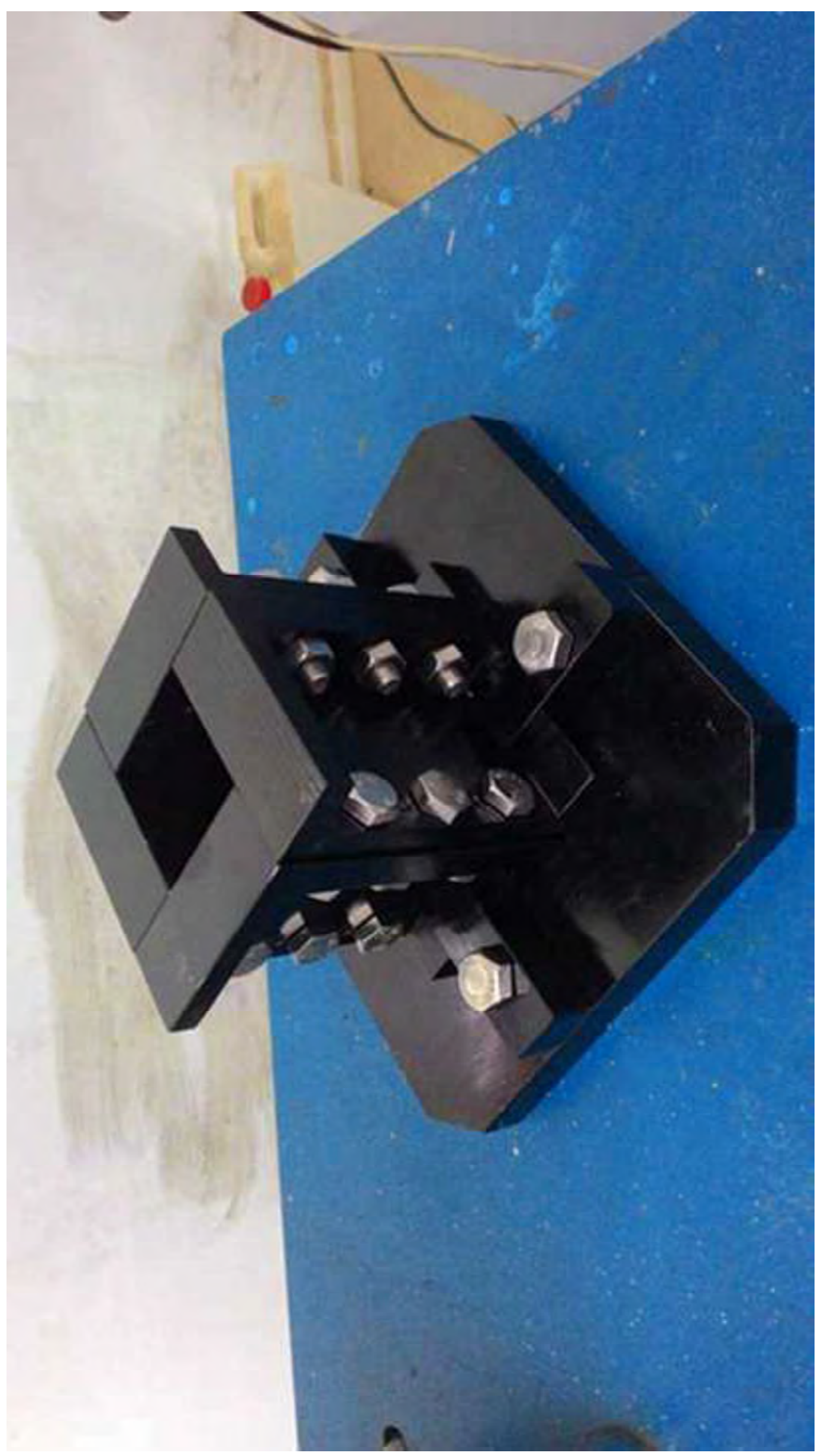




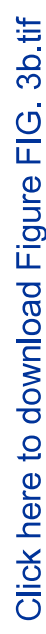

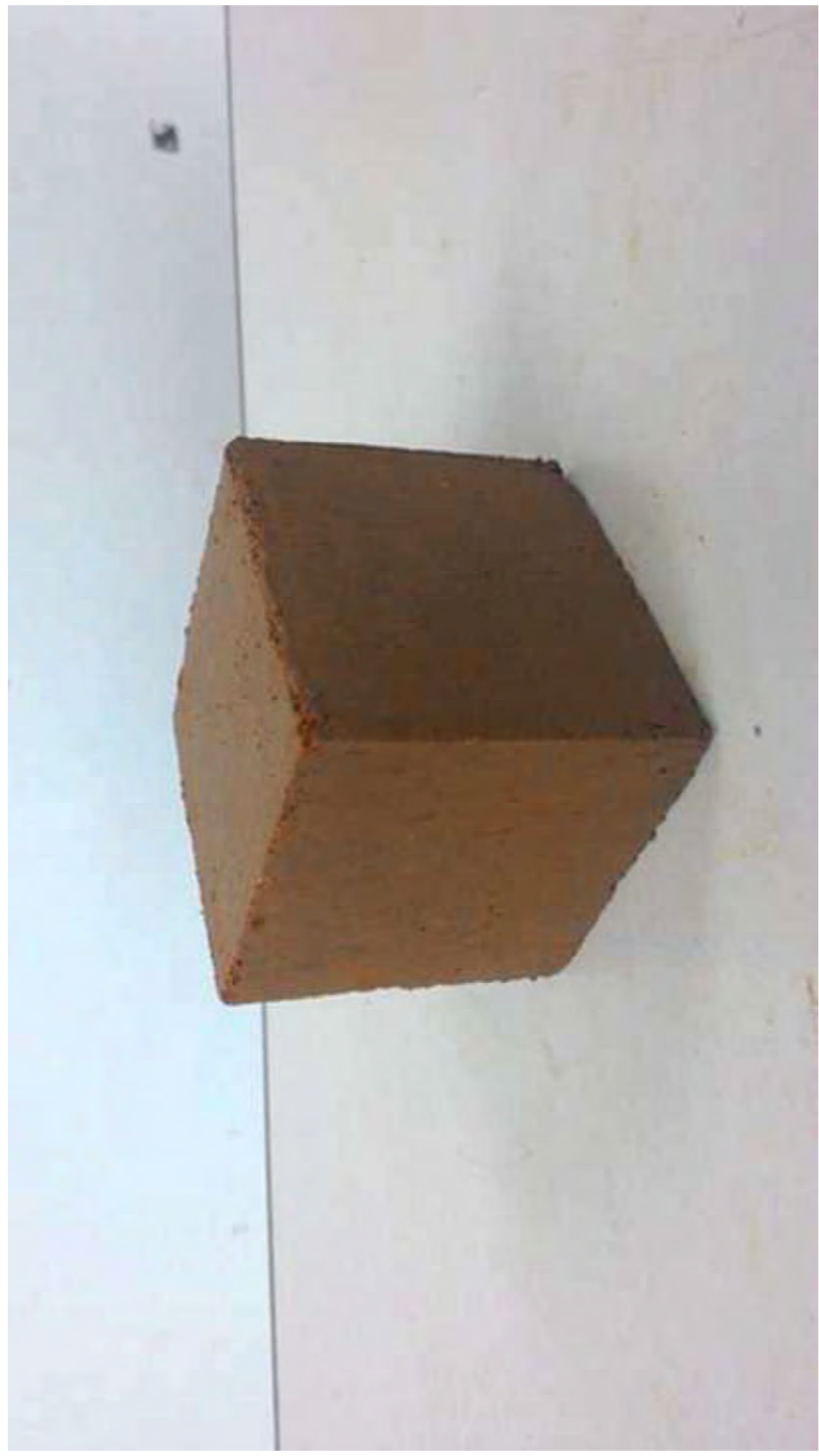




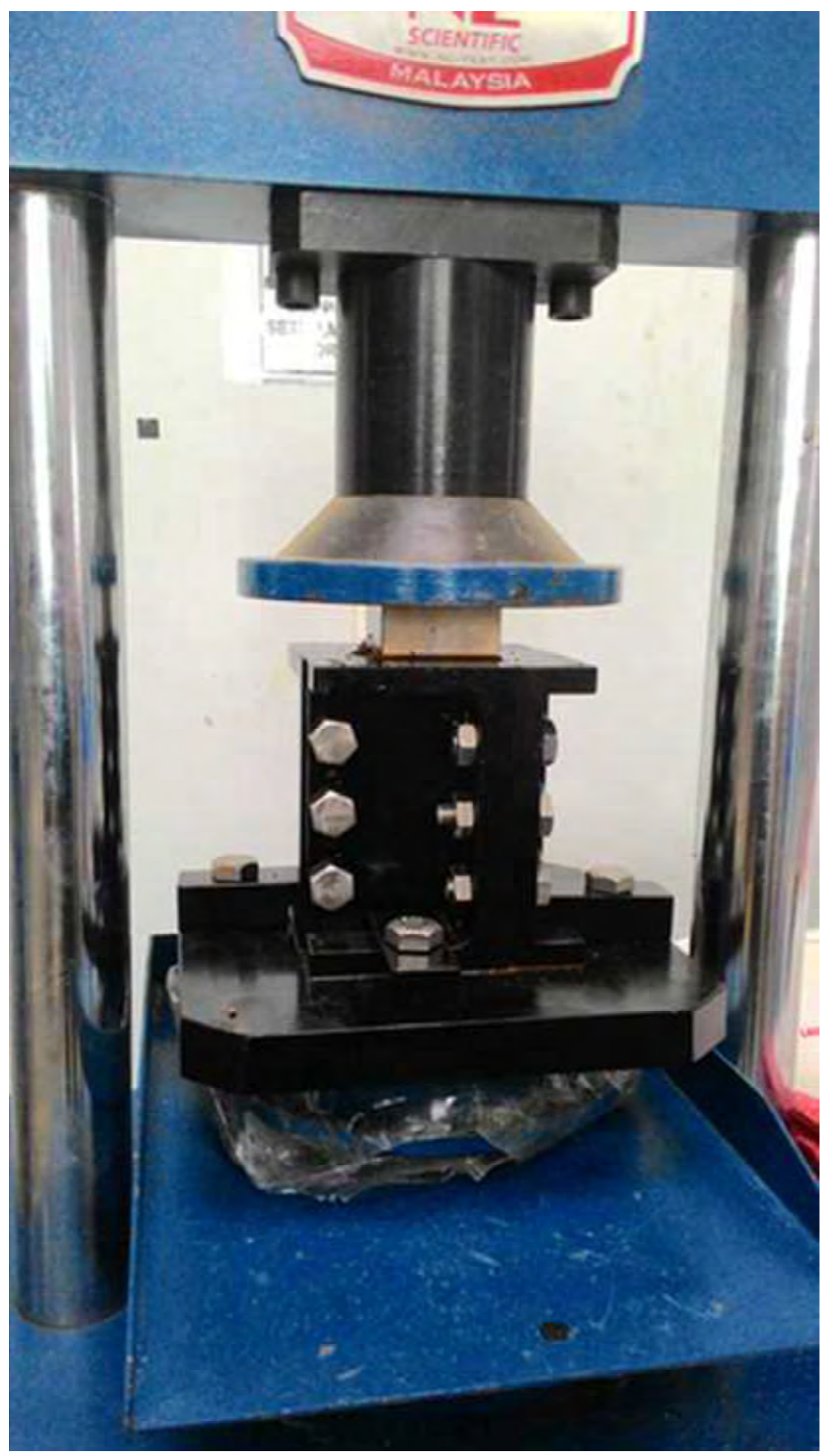




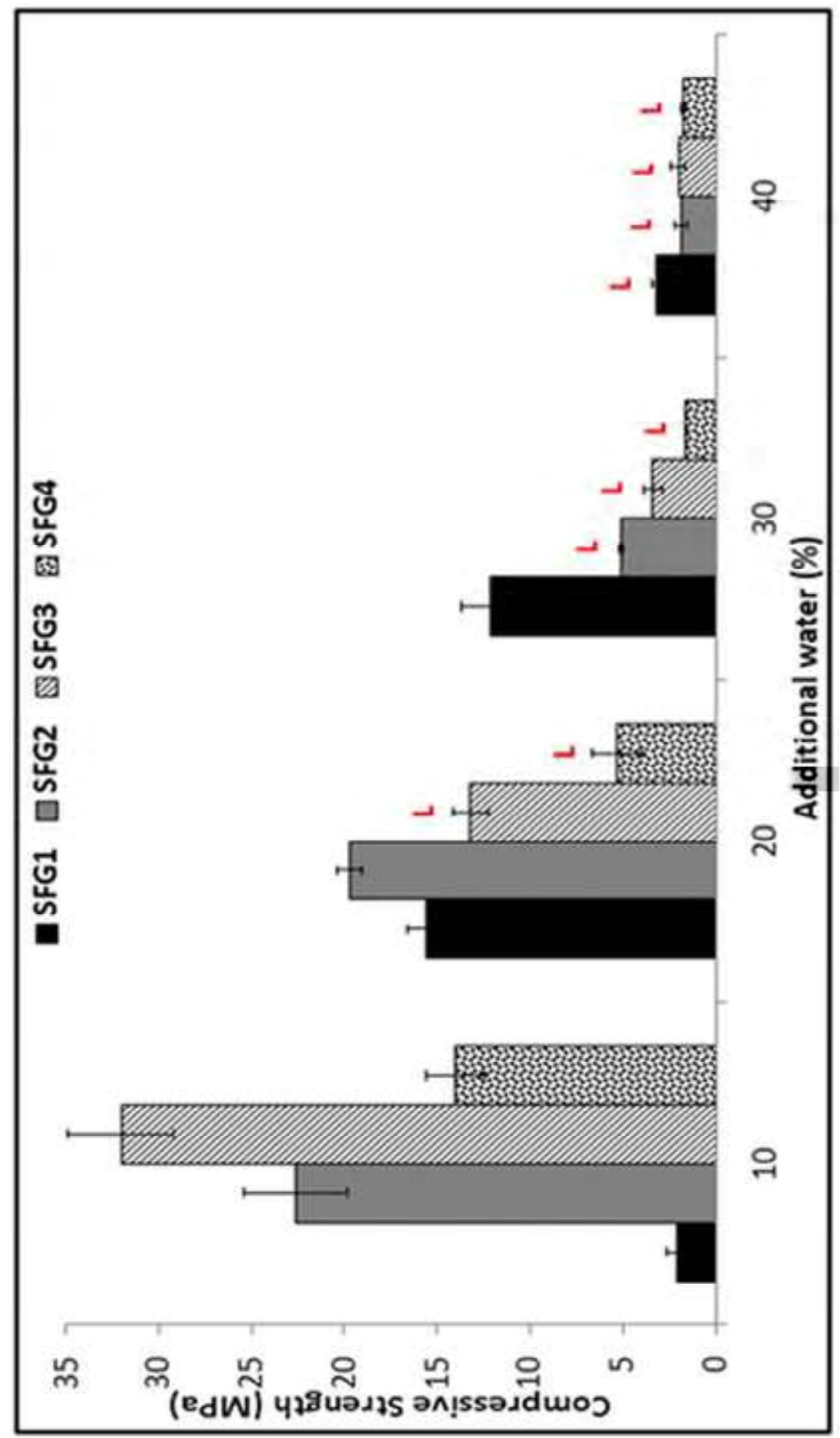




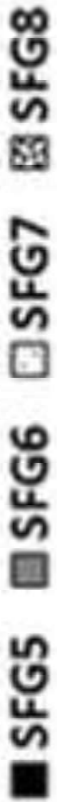

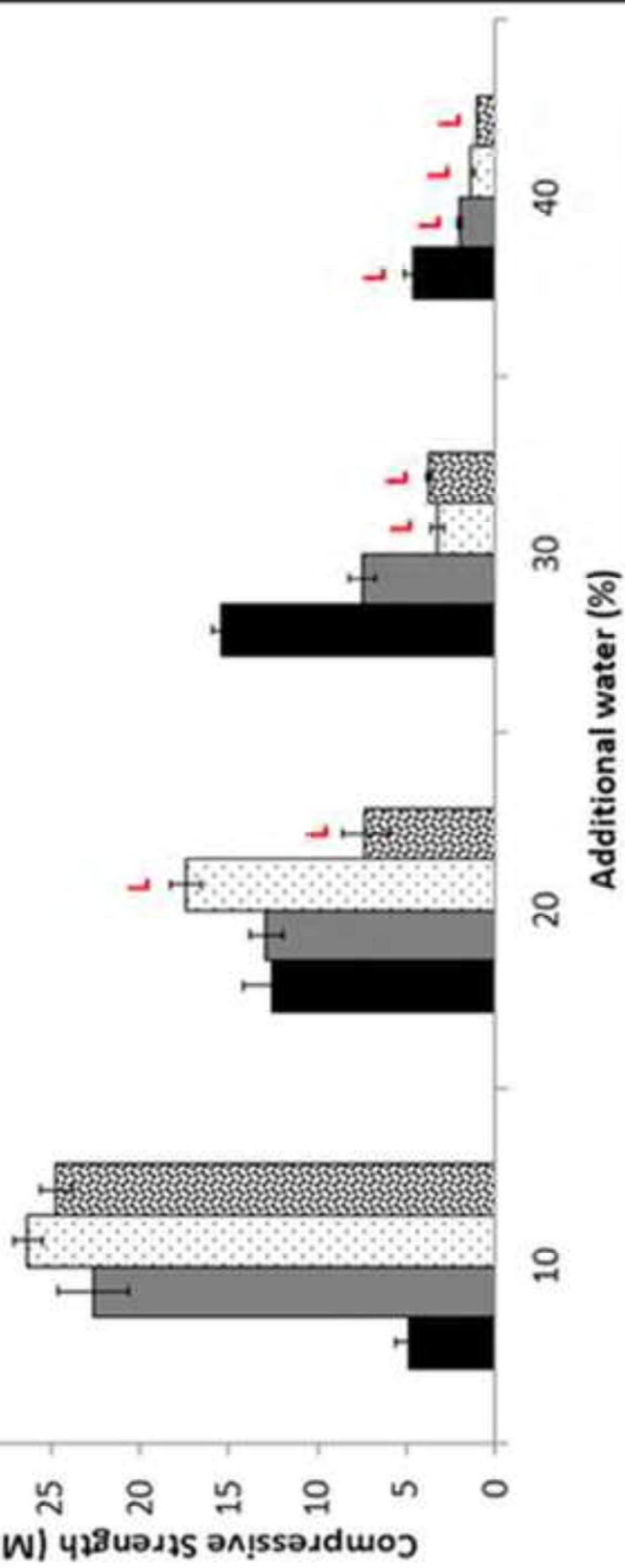




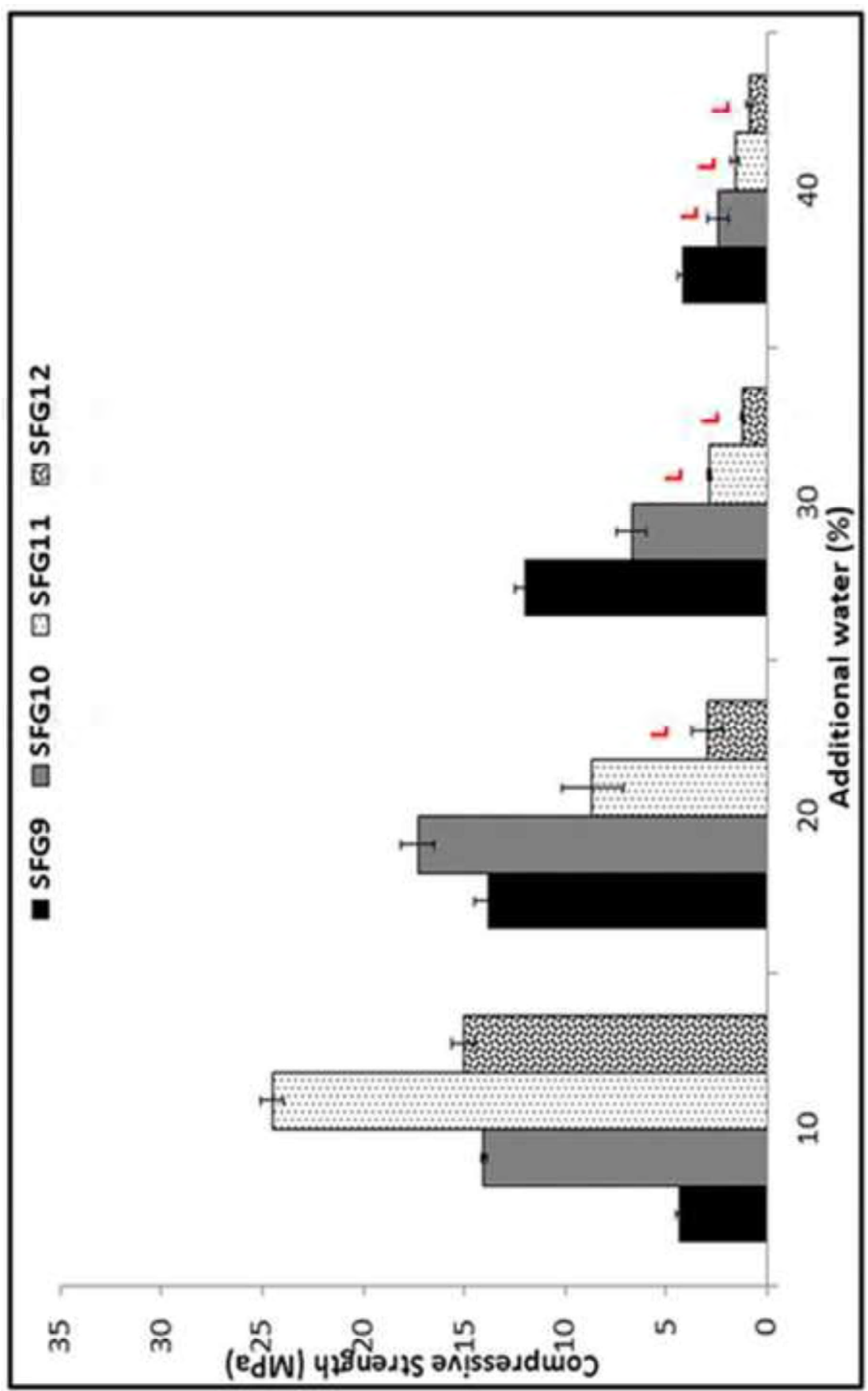




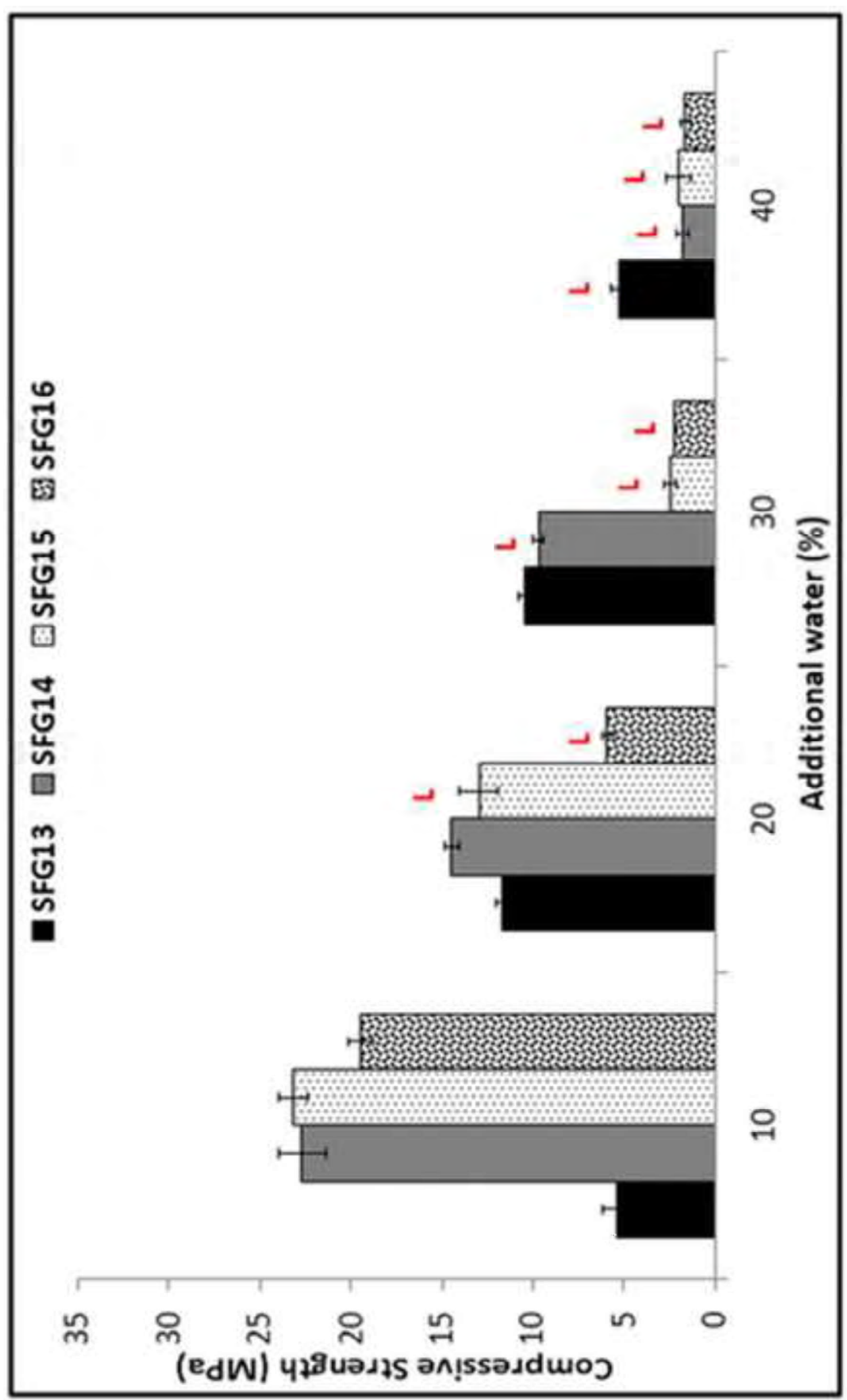




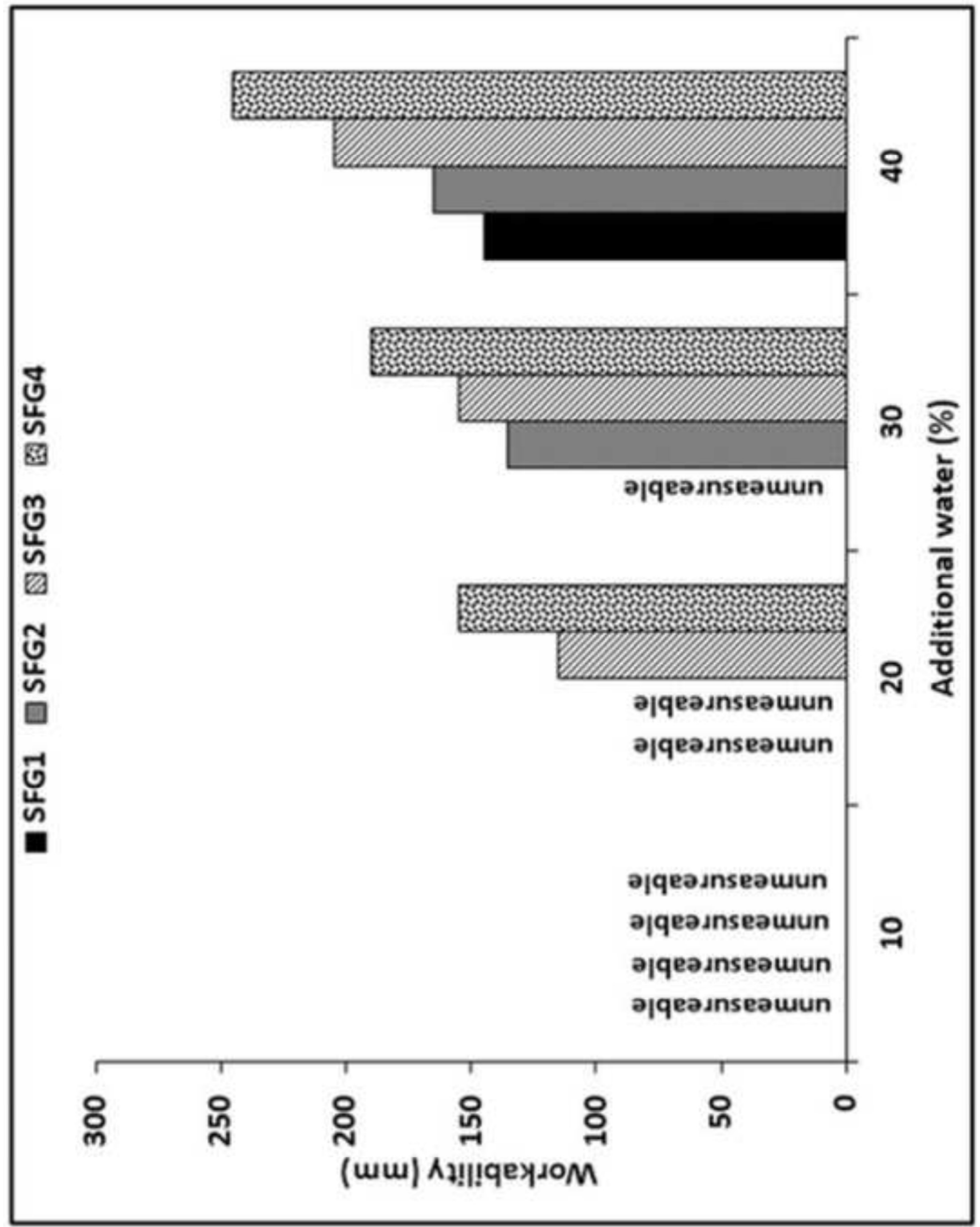




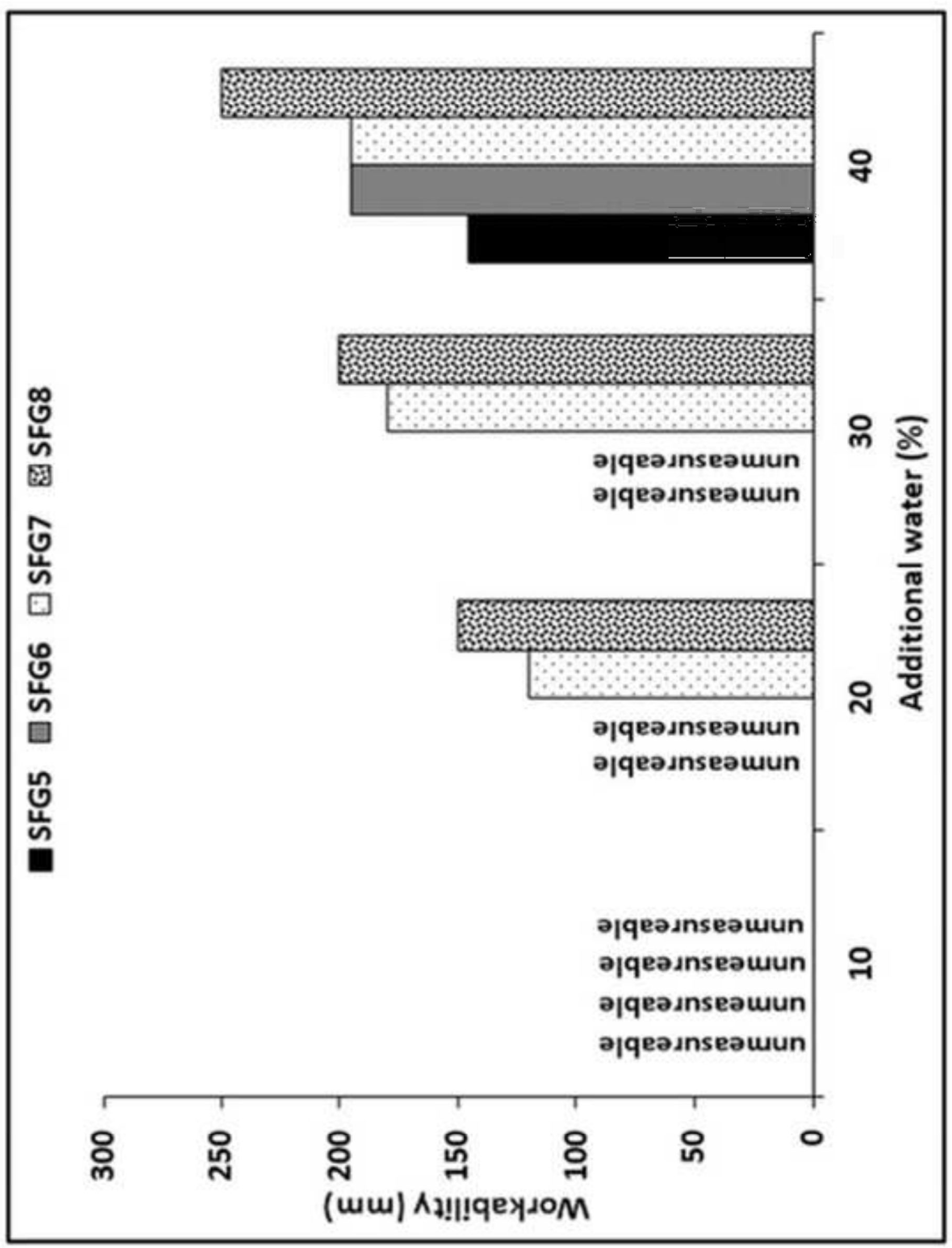




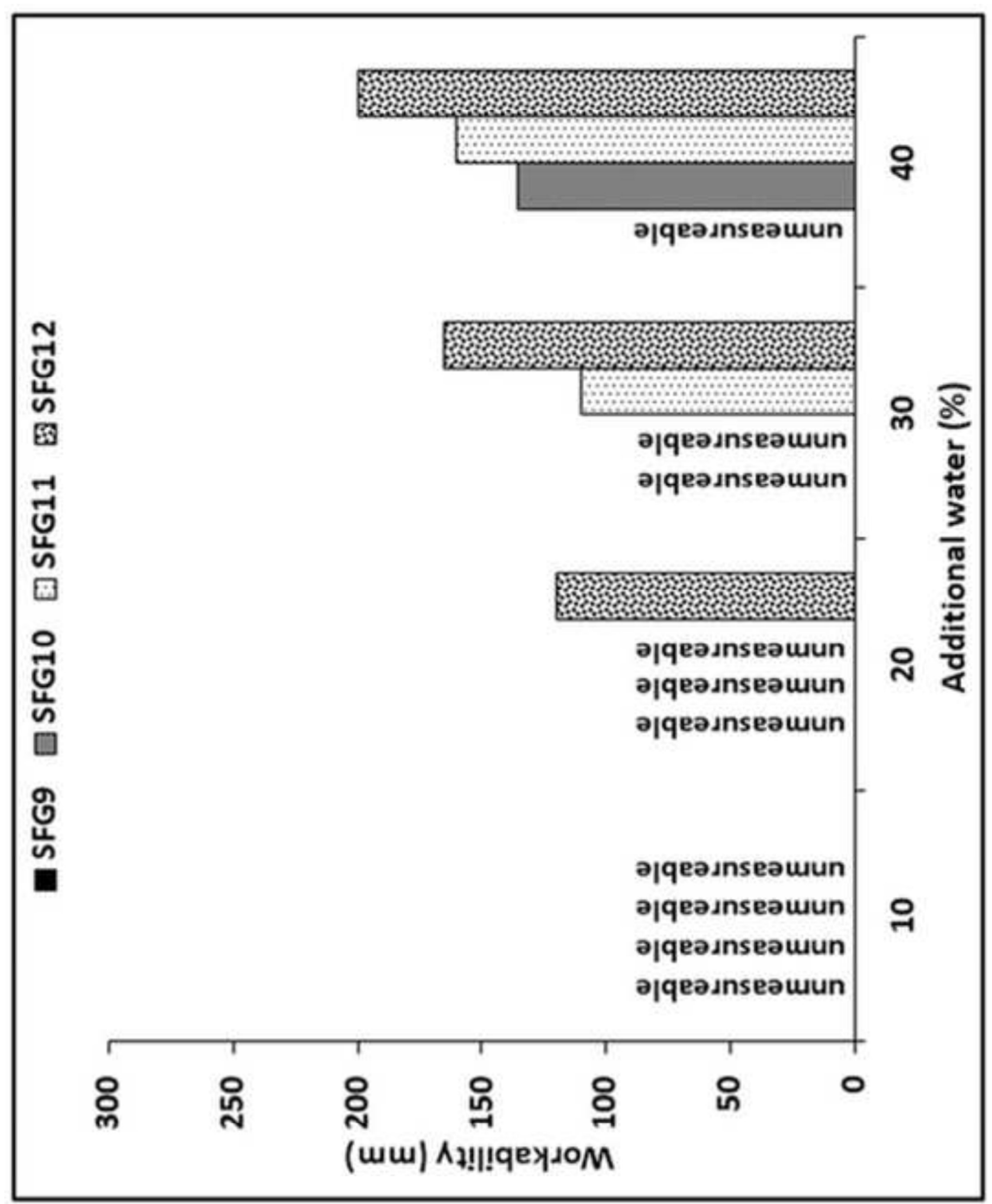

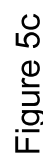




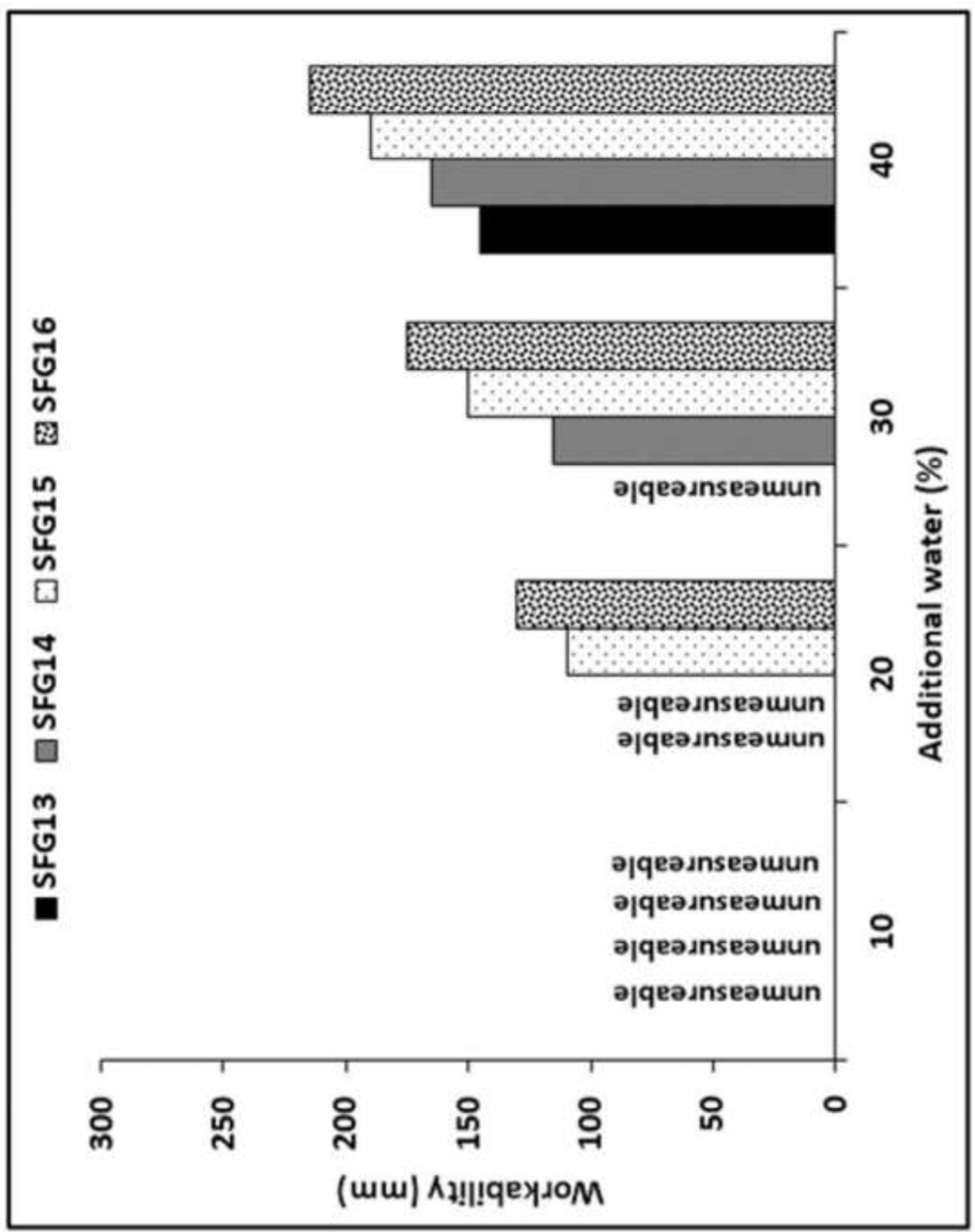




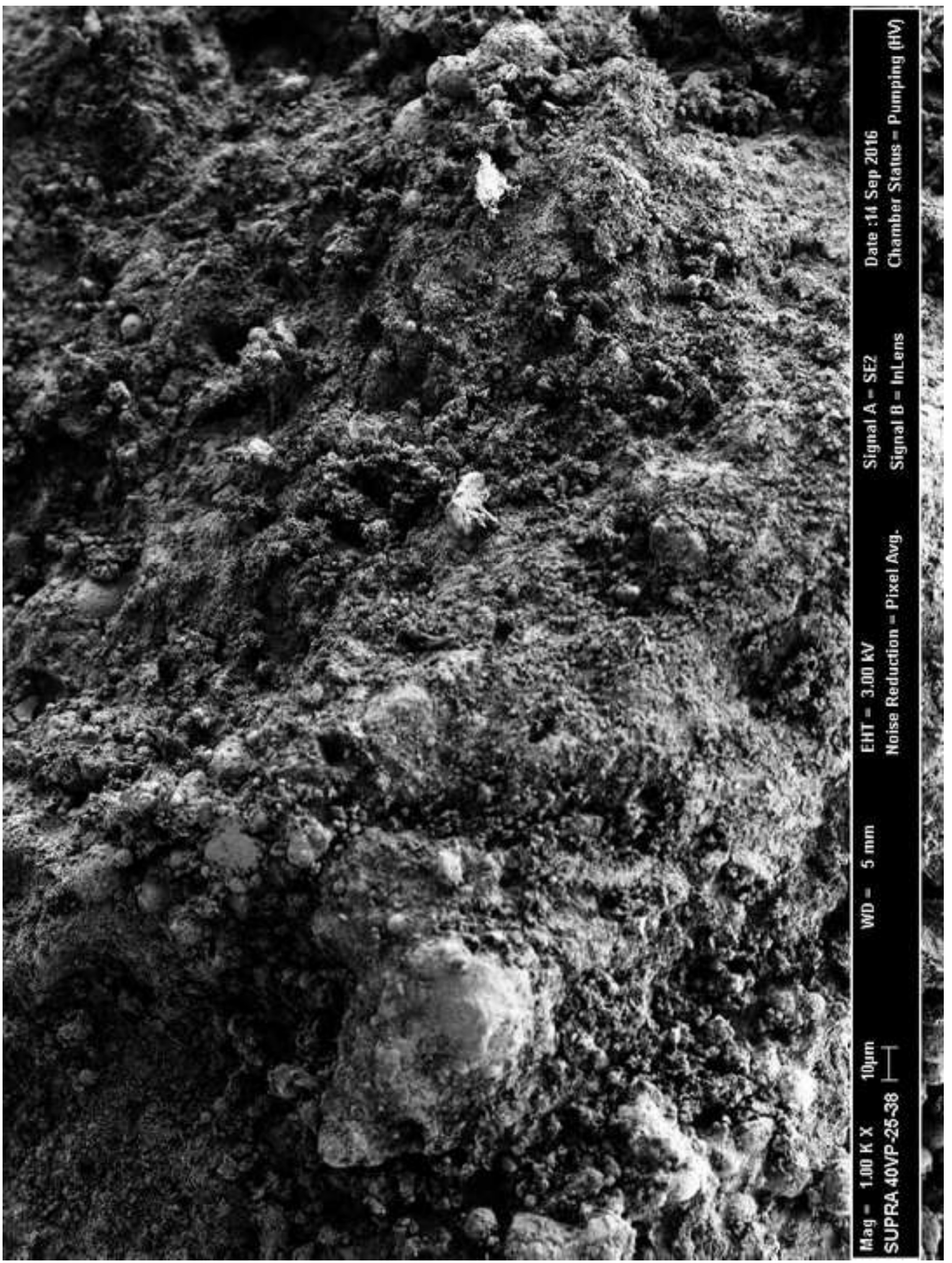




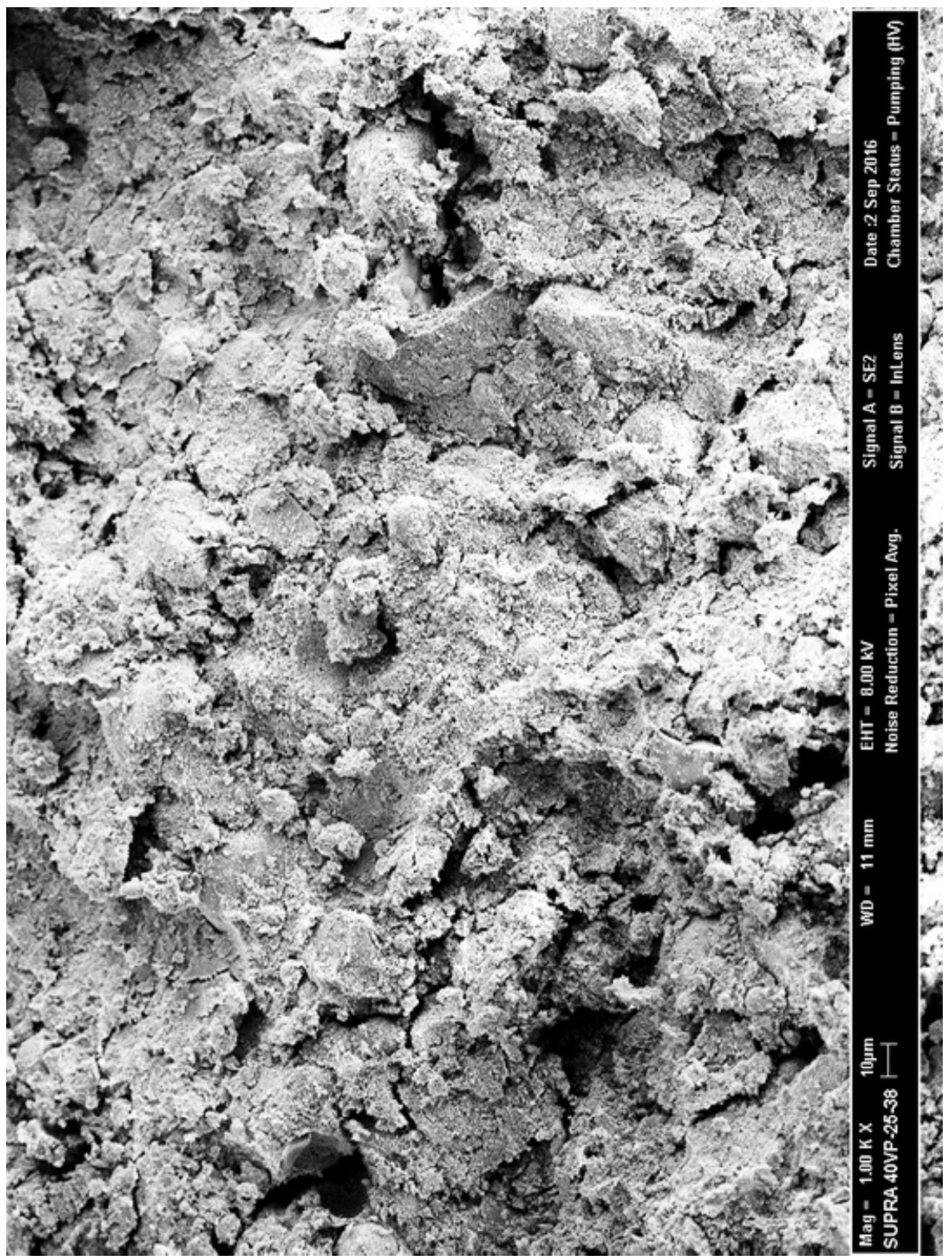




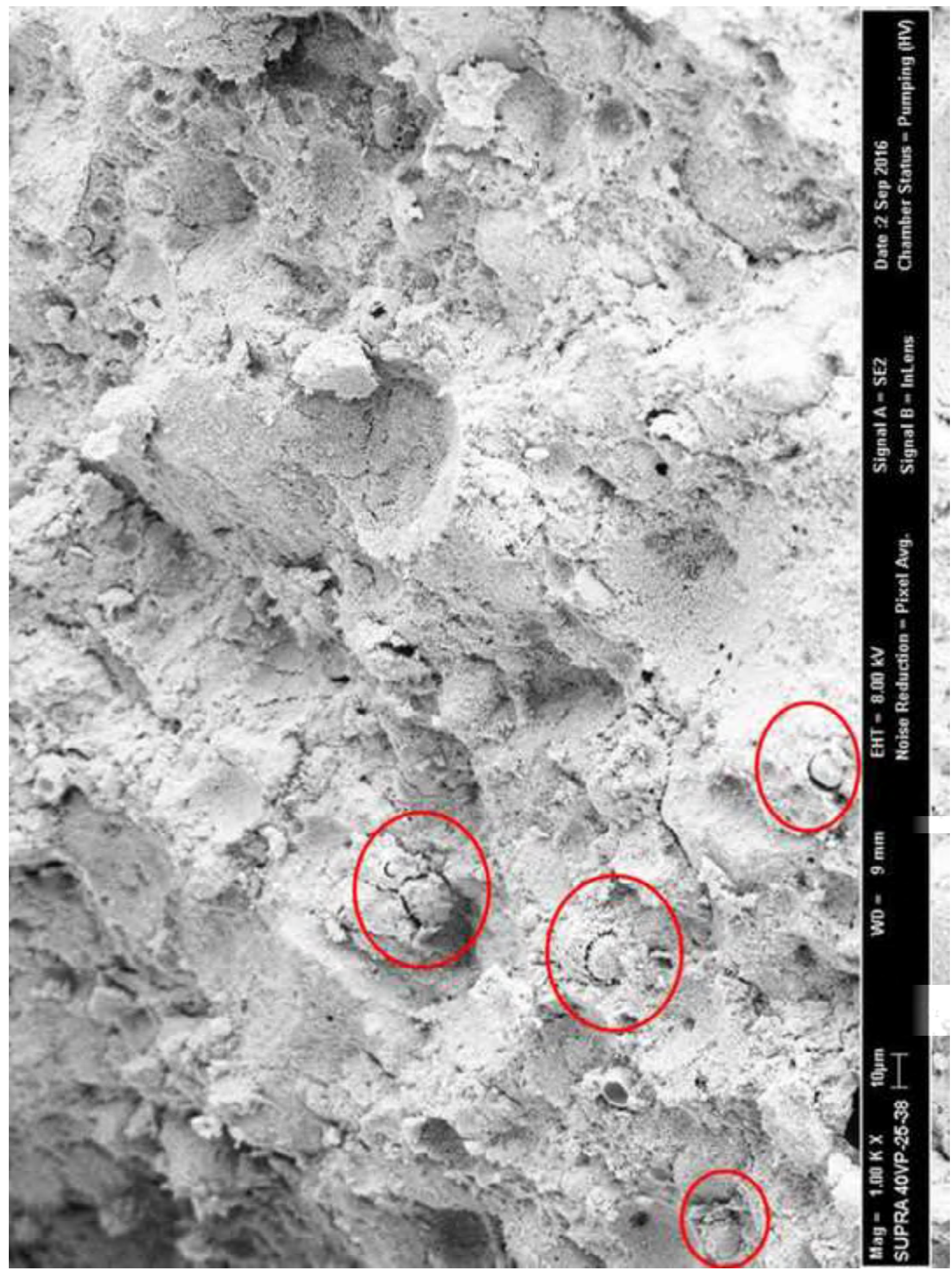




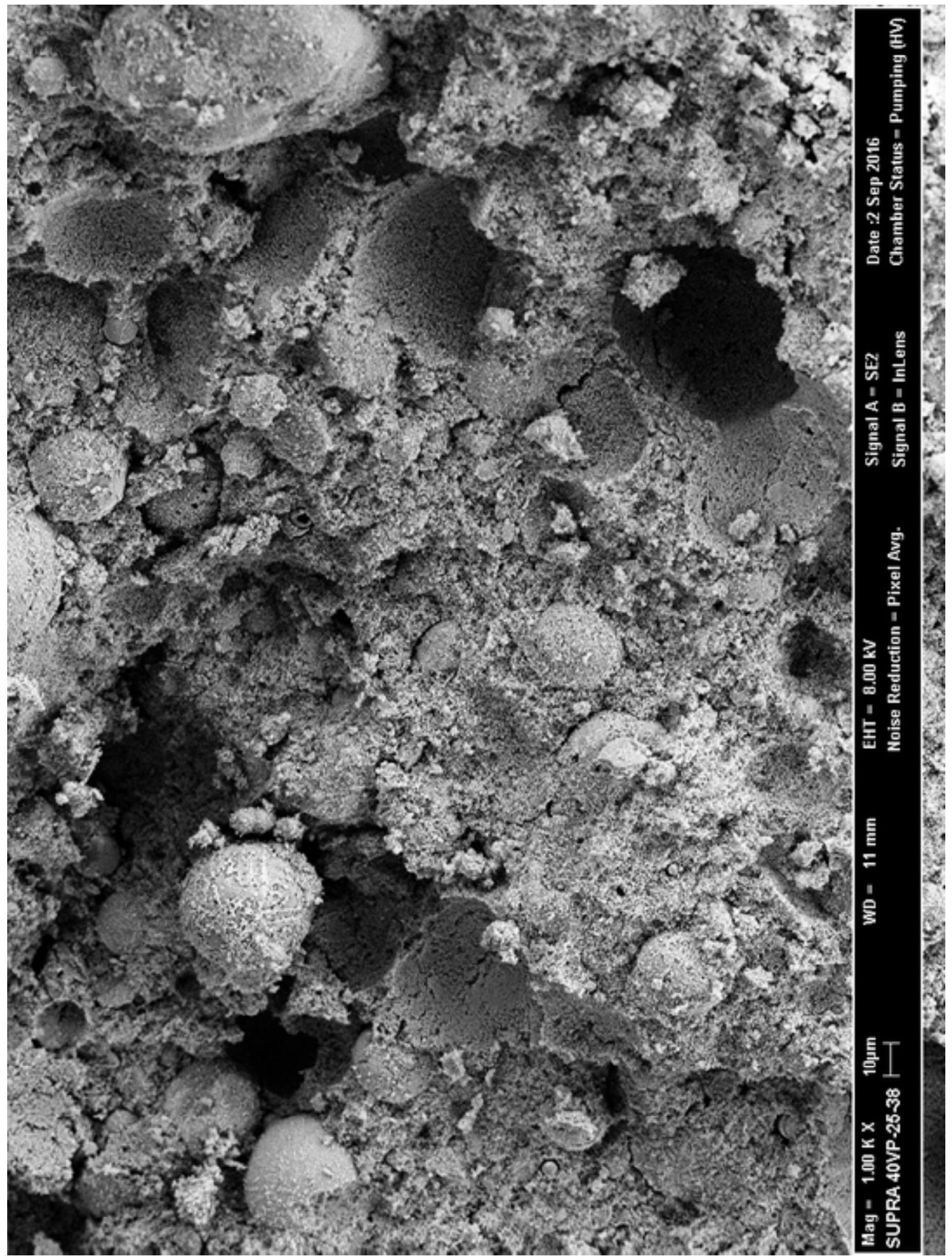




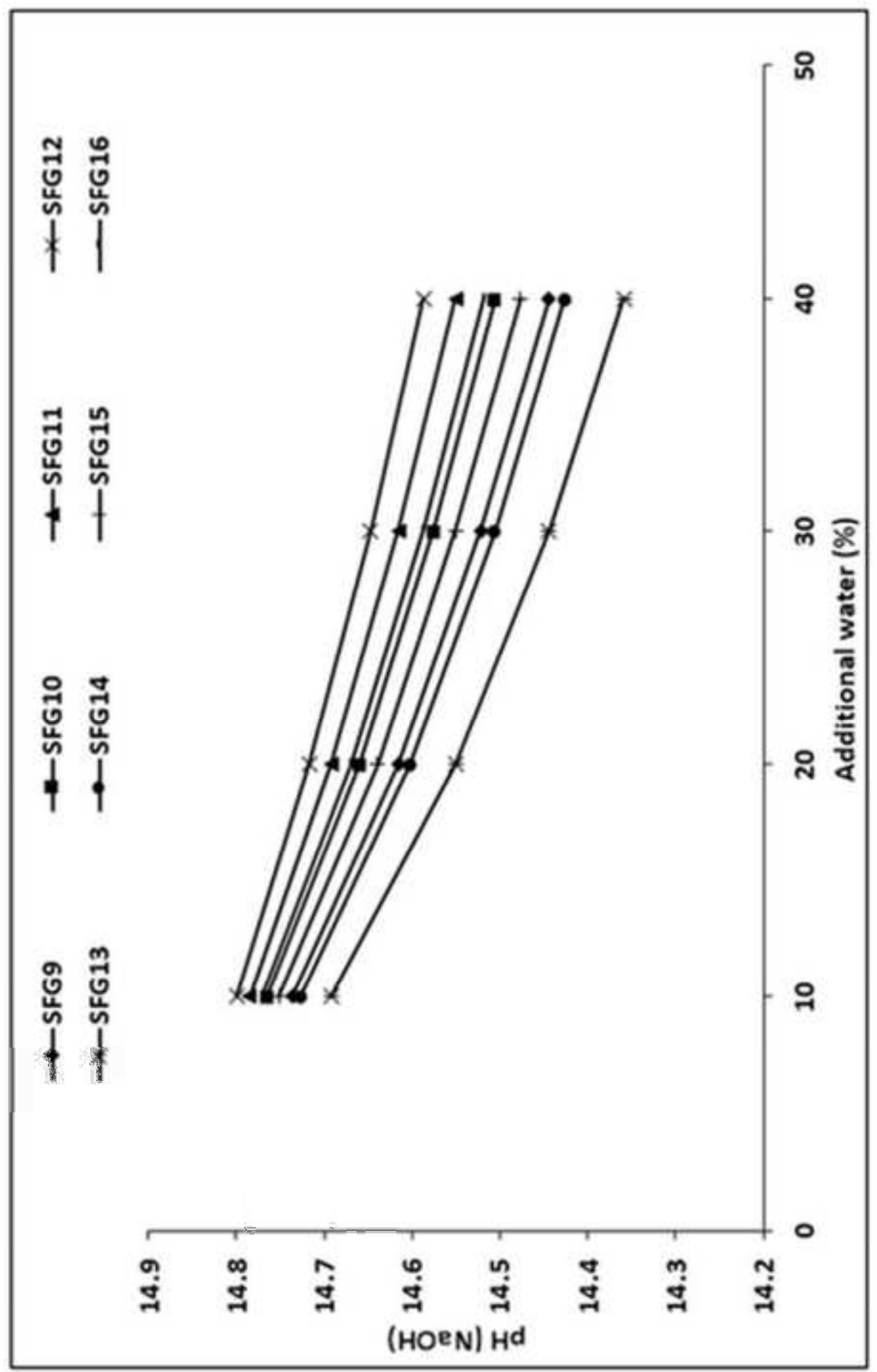

No
$\stackrel{0}{5}$
$i \frac{0}{1}$ 


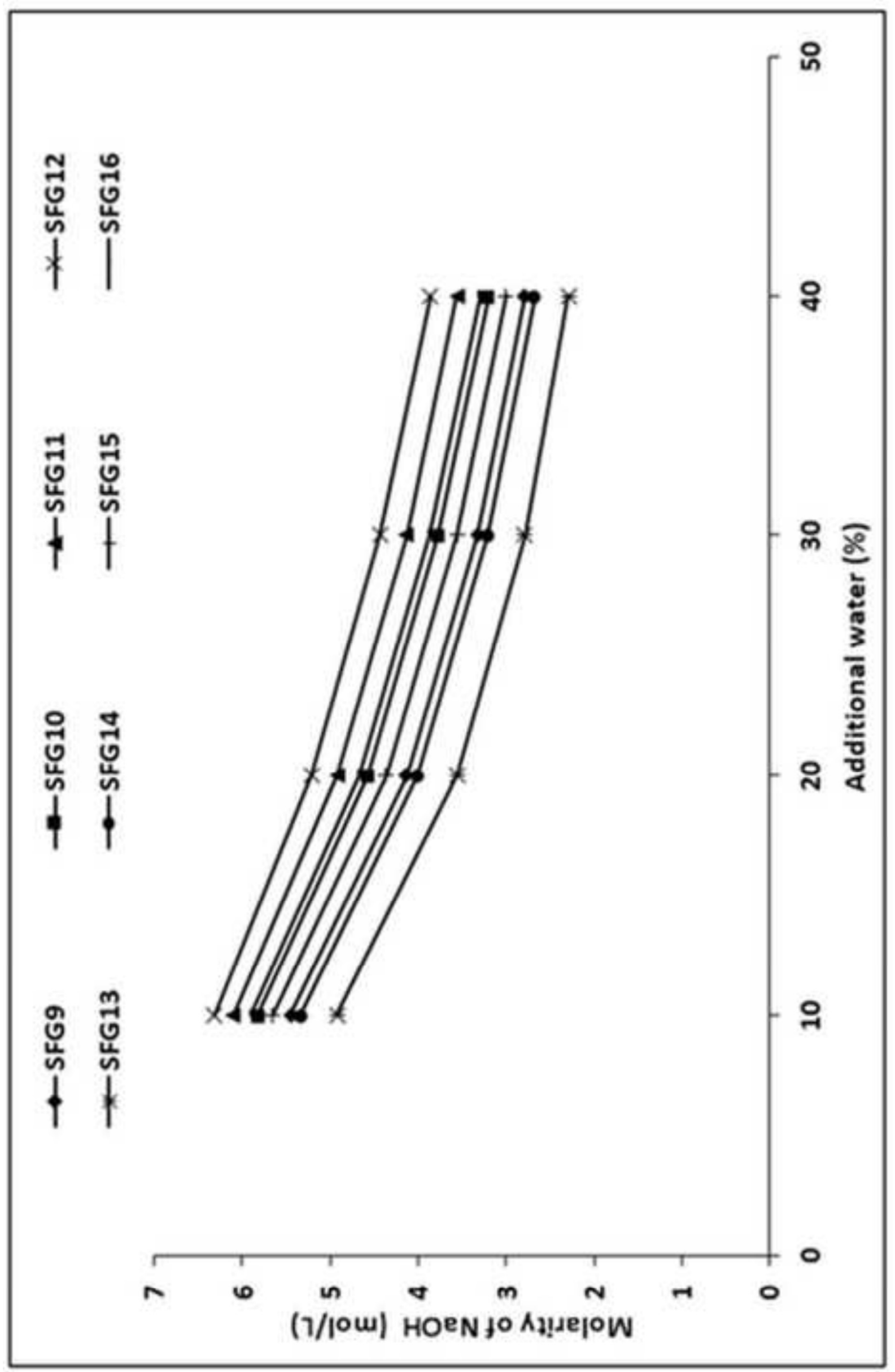

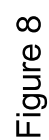




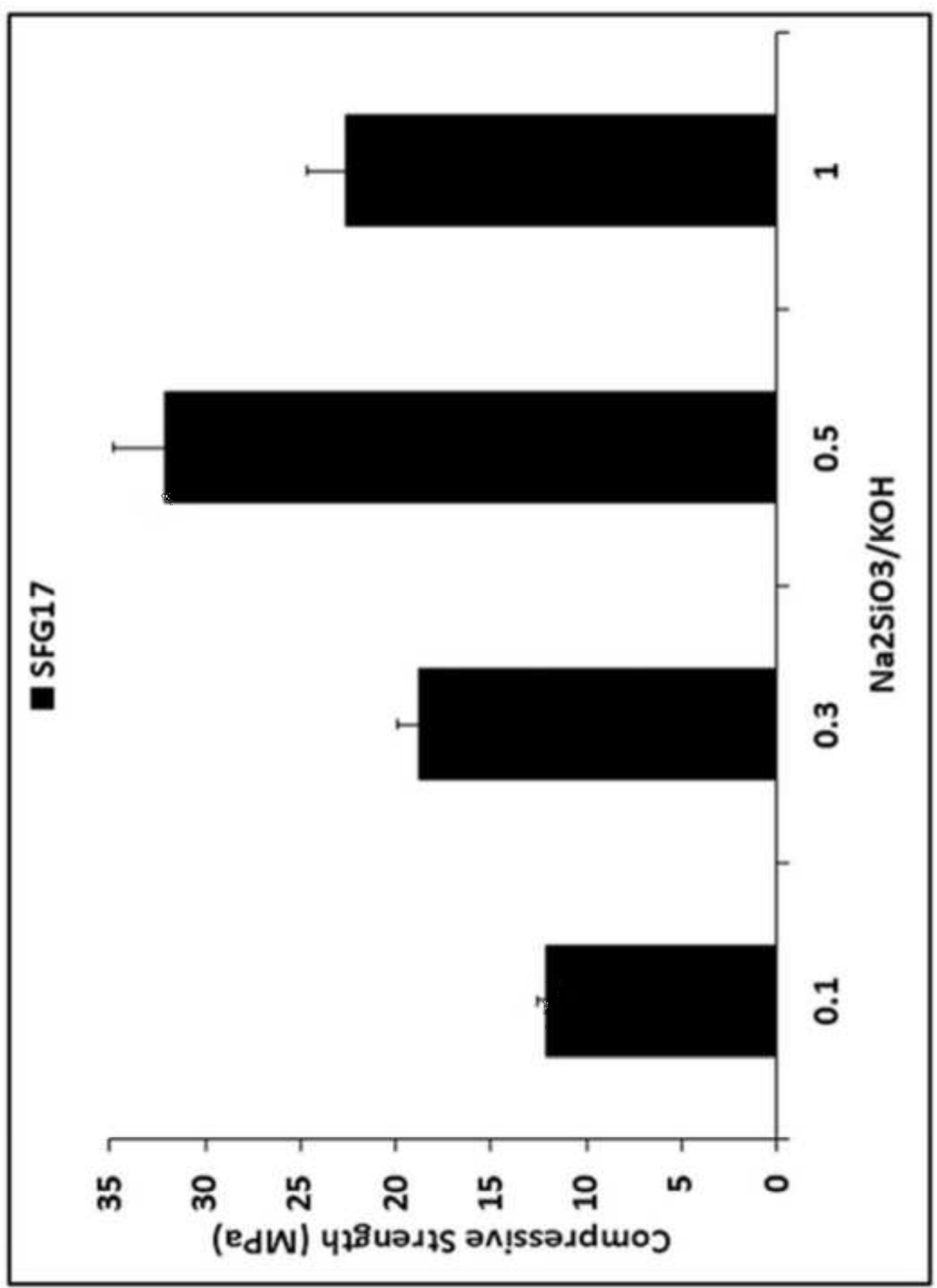


SFG19 口SFG20 घSFG21
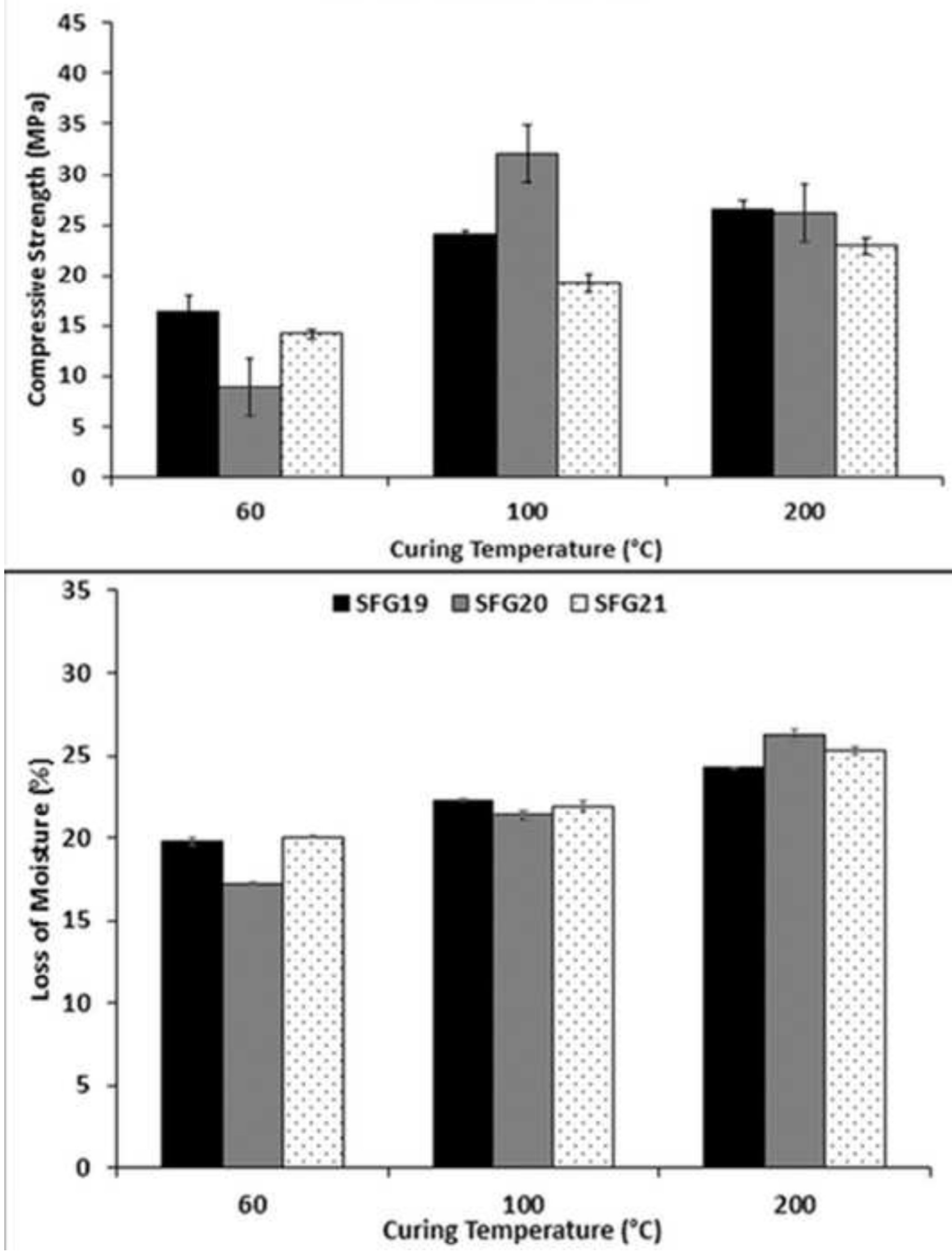
SFG22 ISFG23 DSFG24

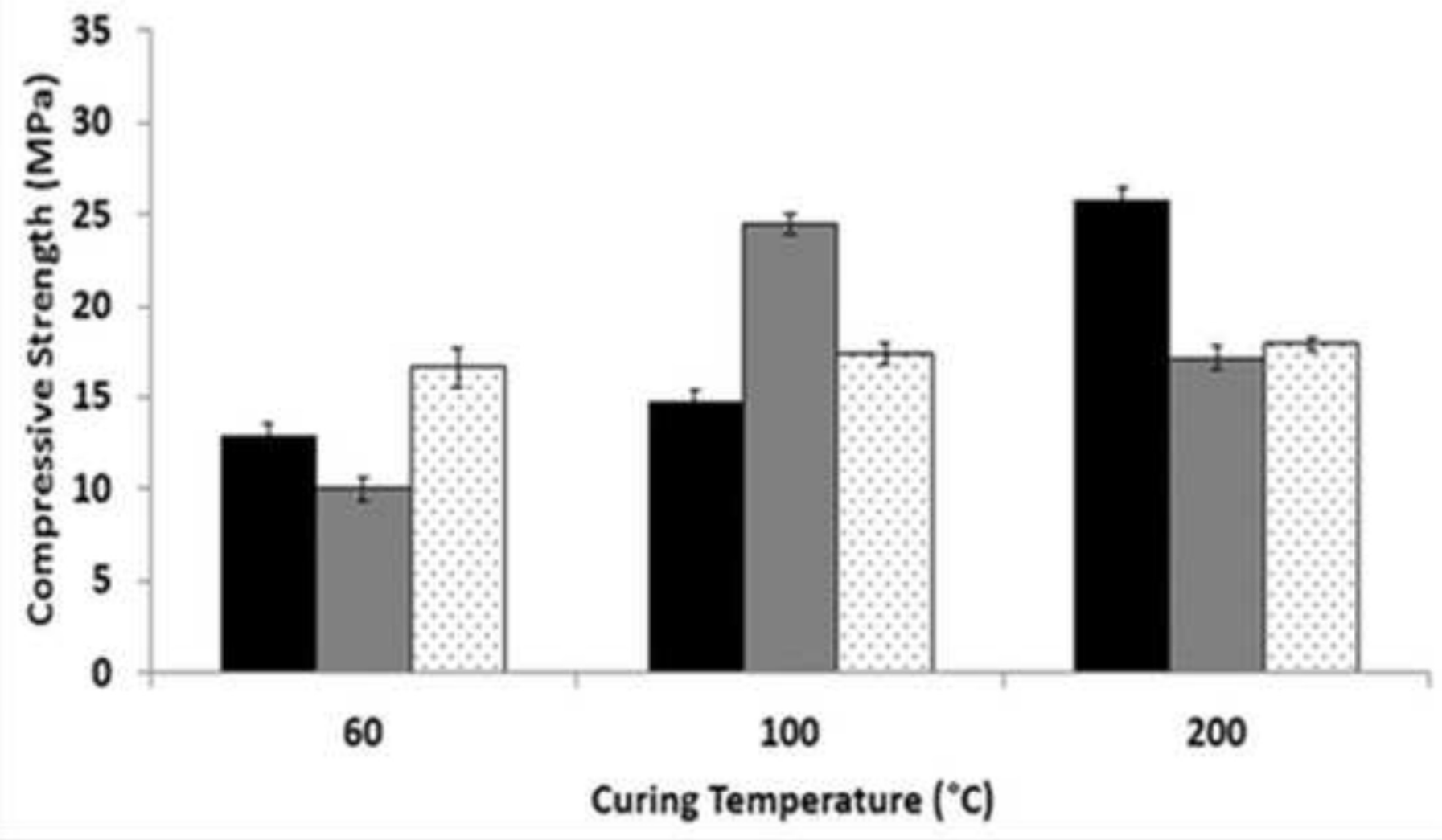

—SFG22 口SFG23 DSFG24

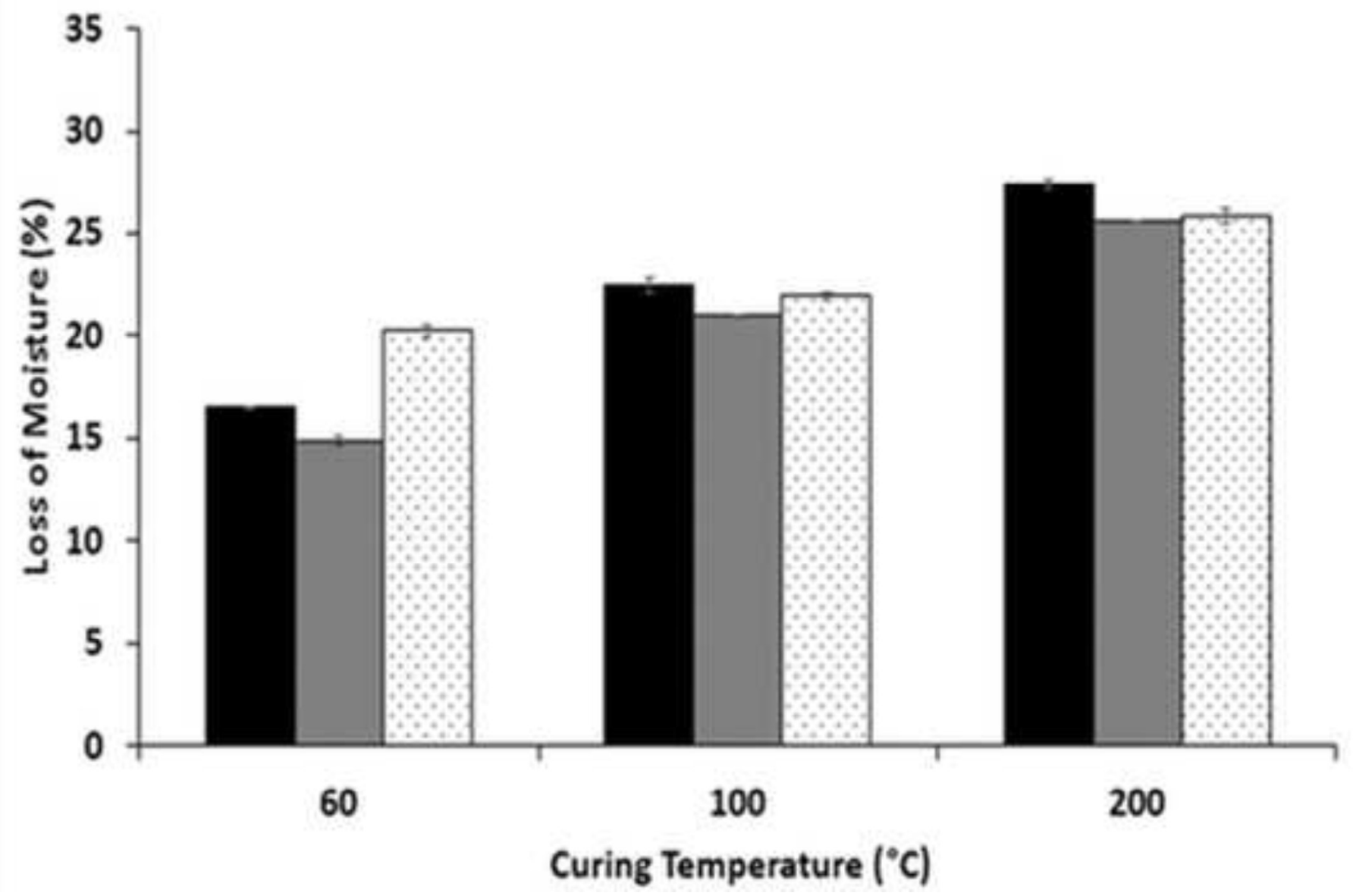




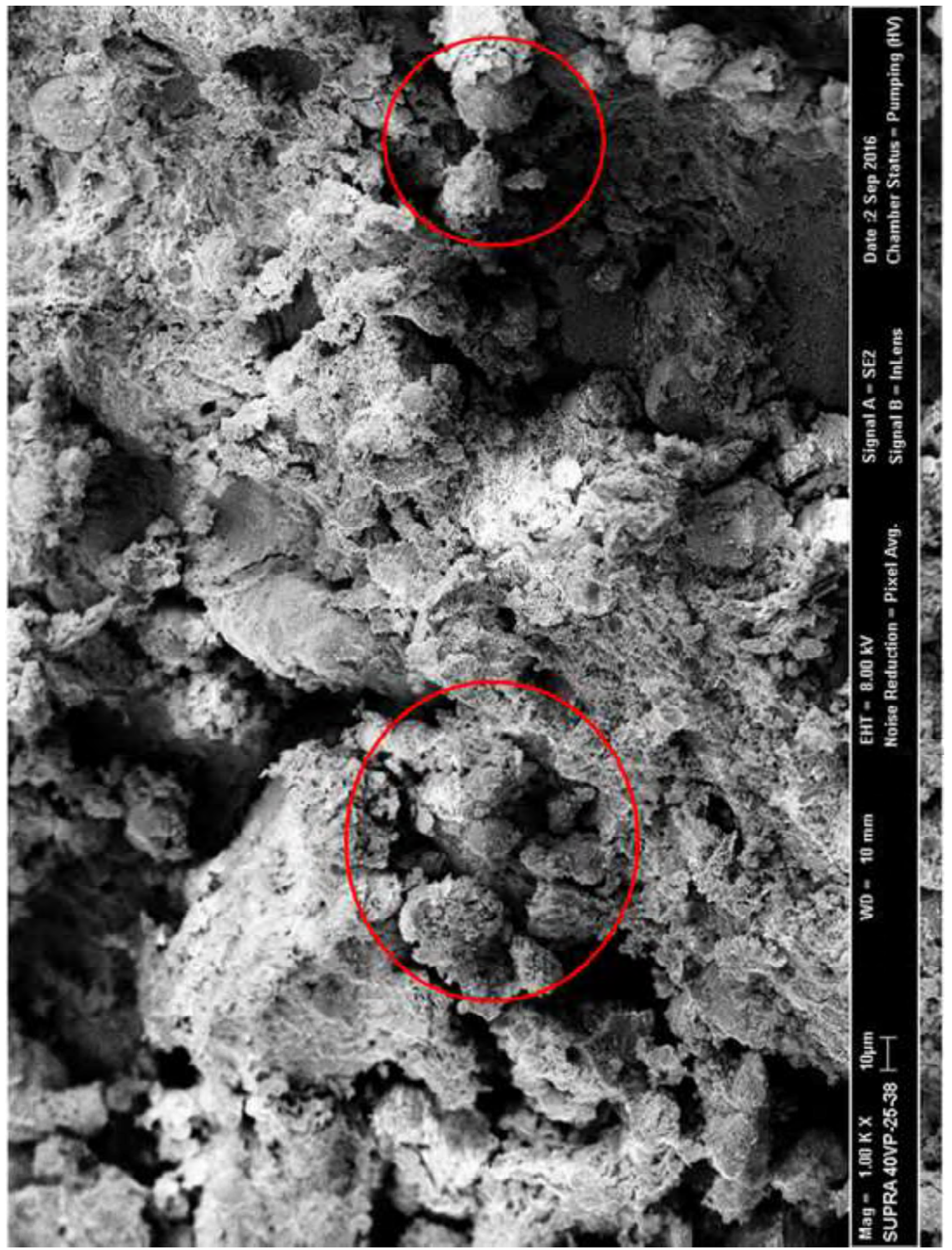




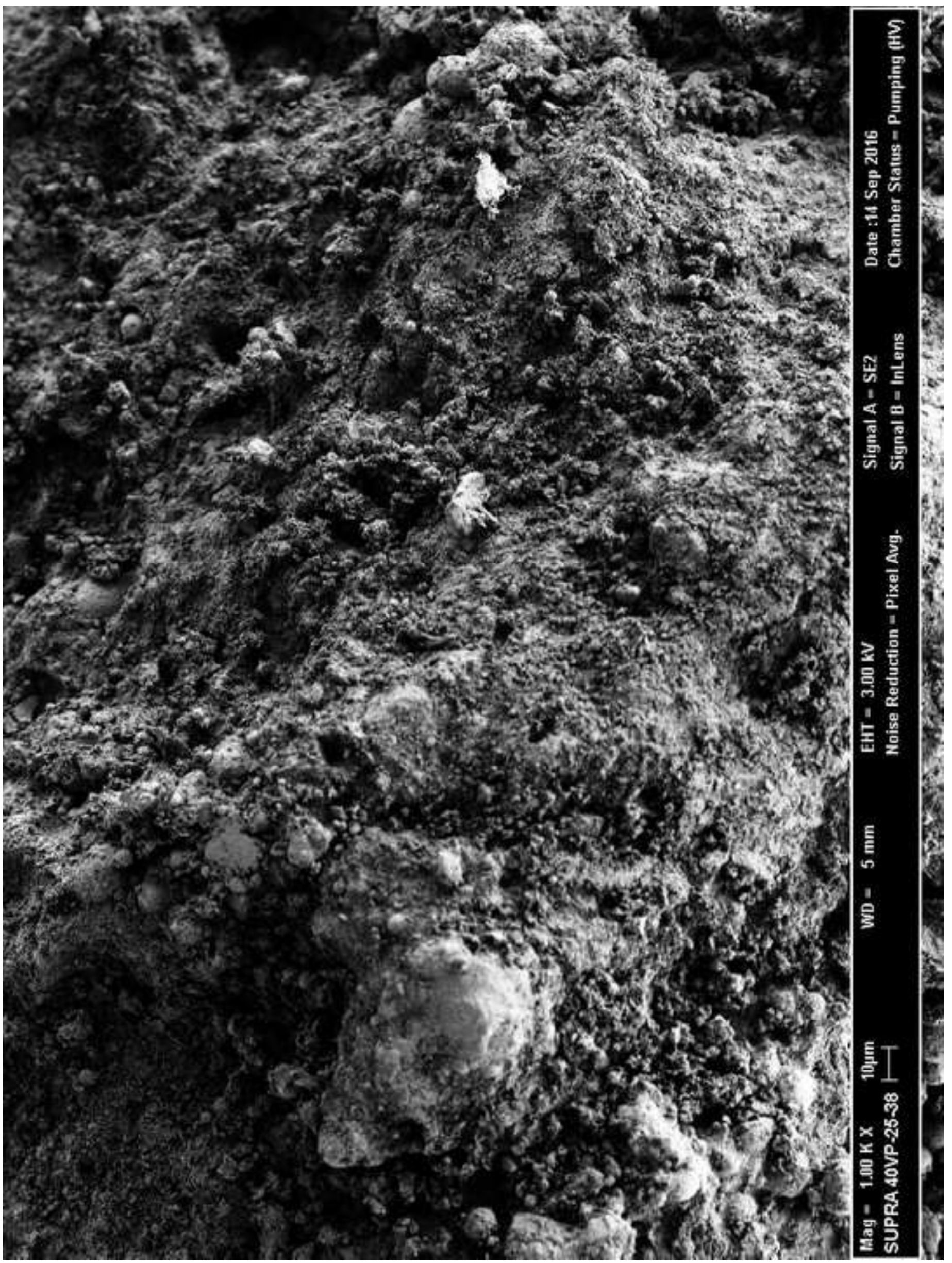




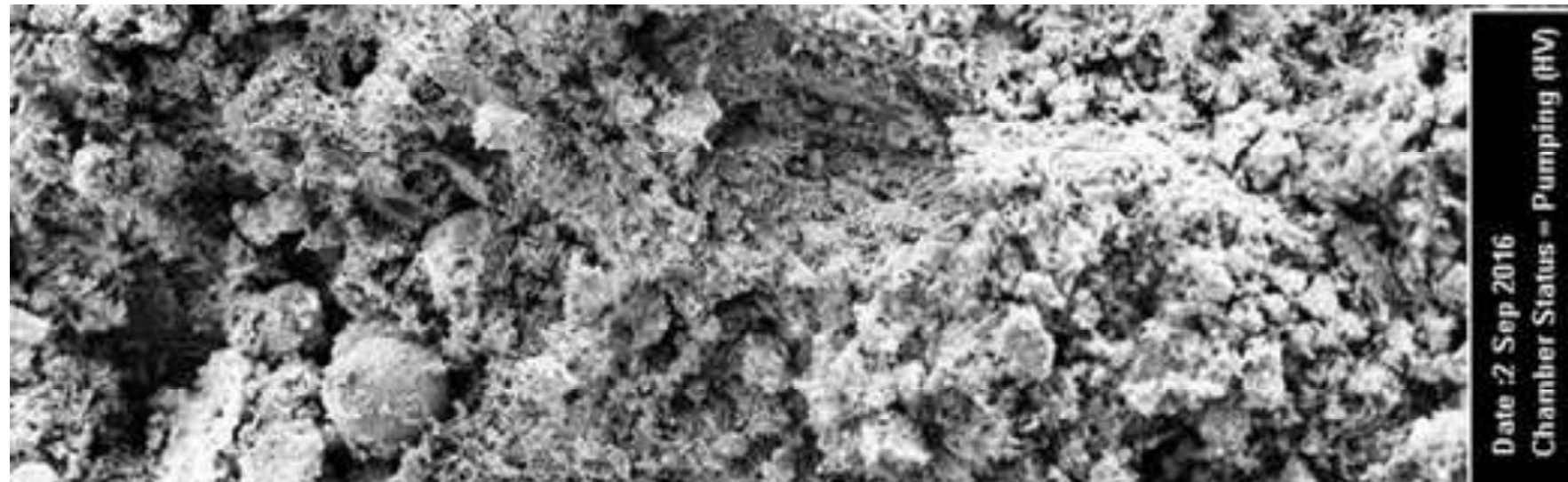

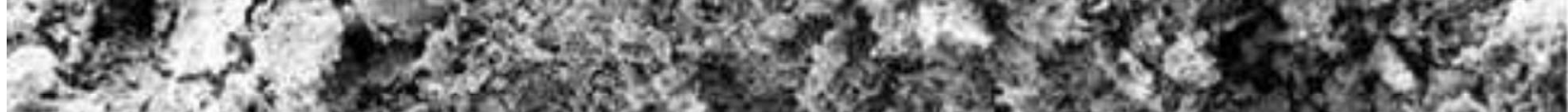
H.

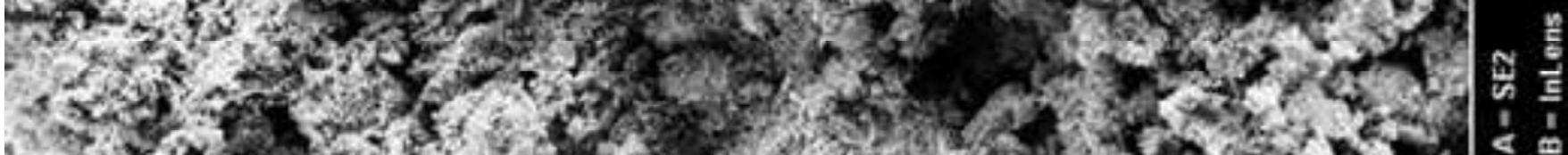

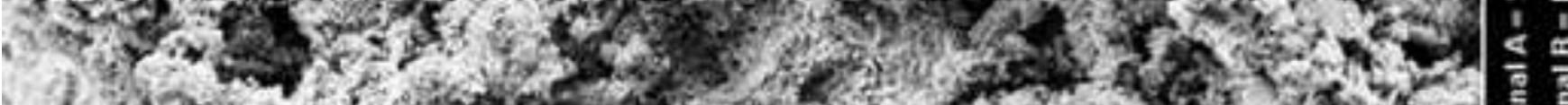

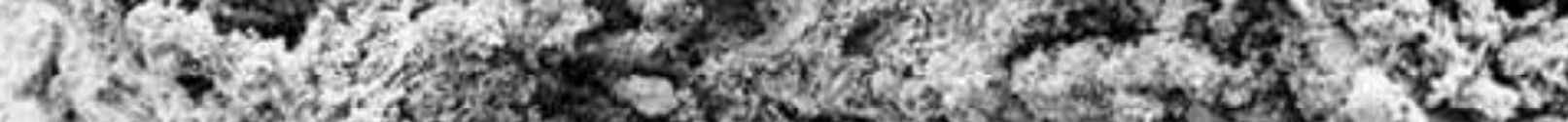

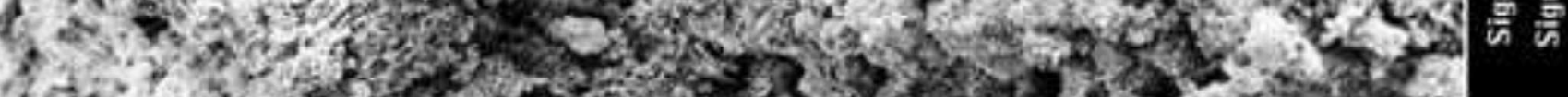

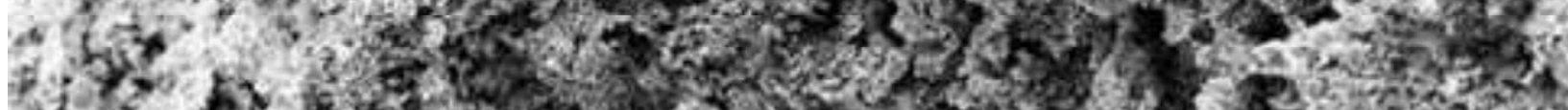

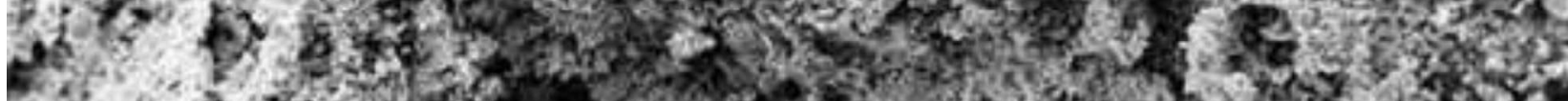

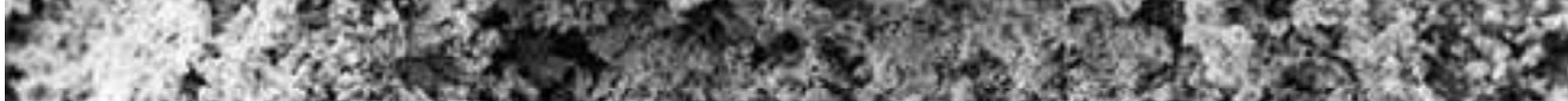

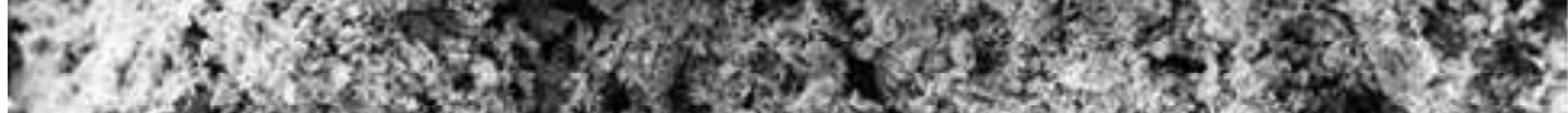

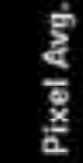

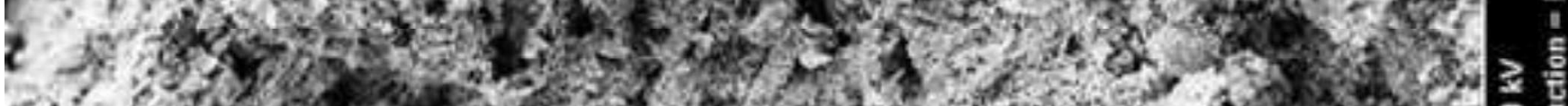

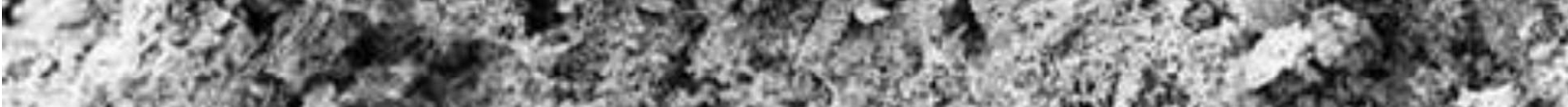
Fis

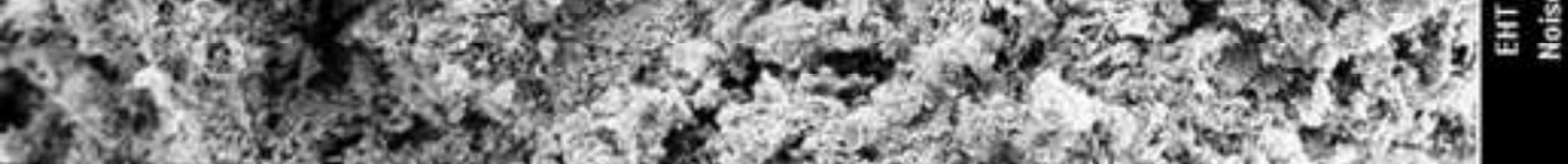

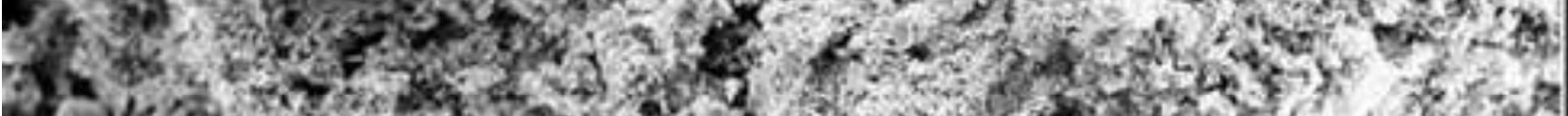

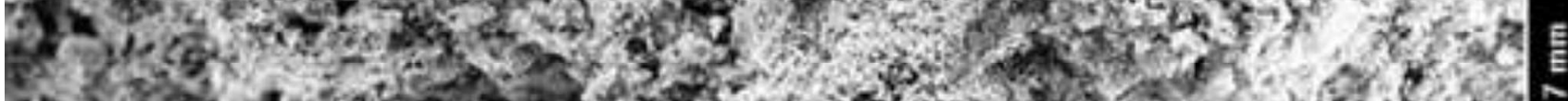

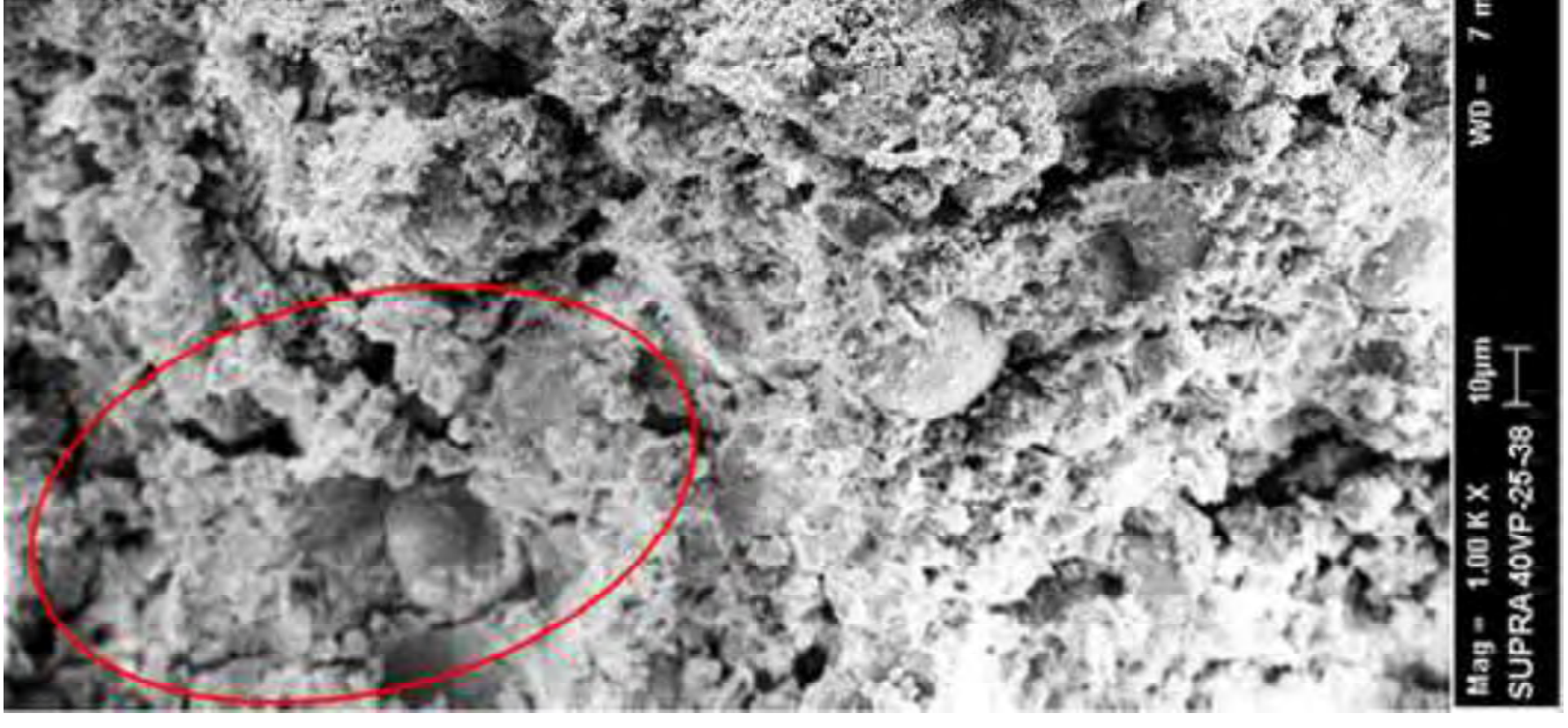




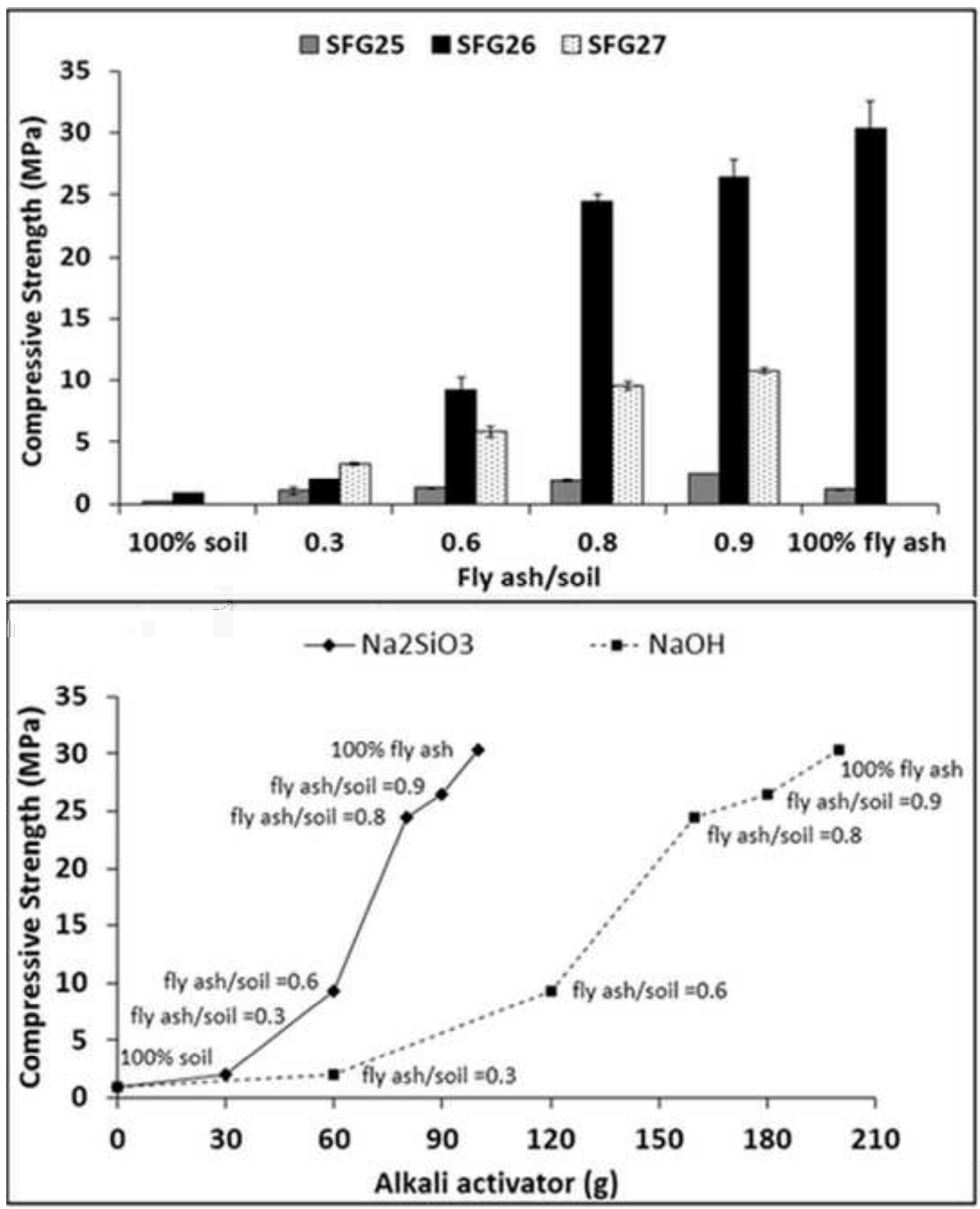




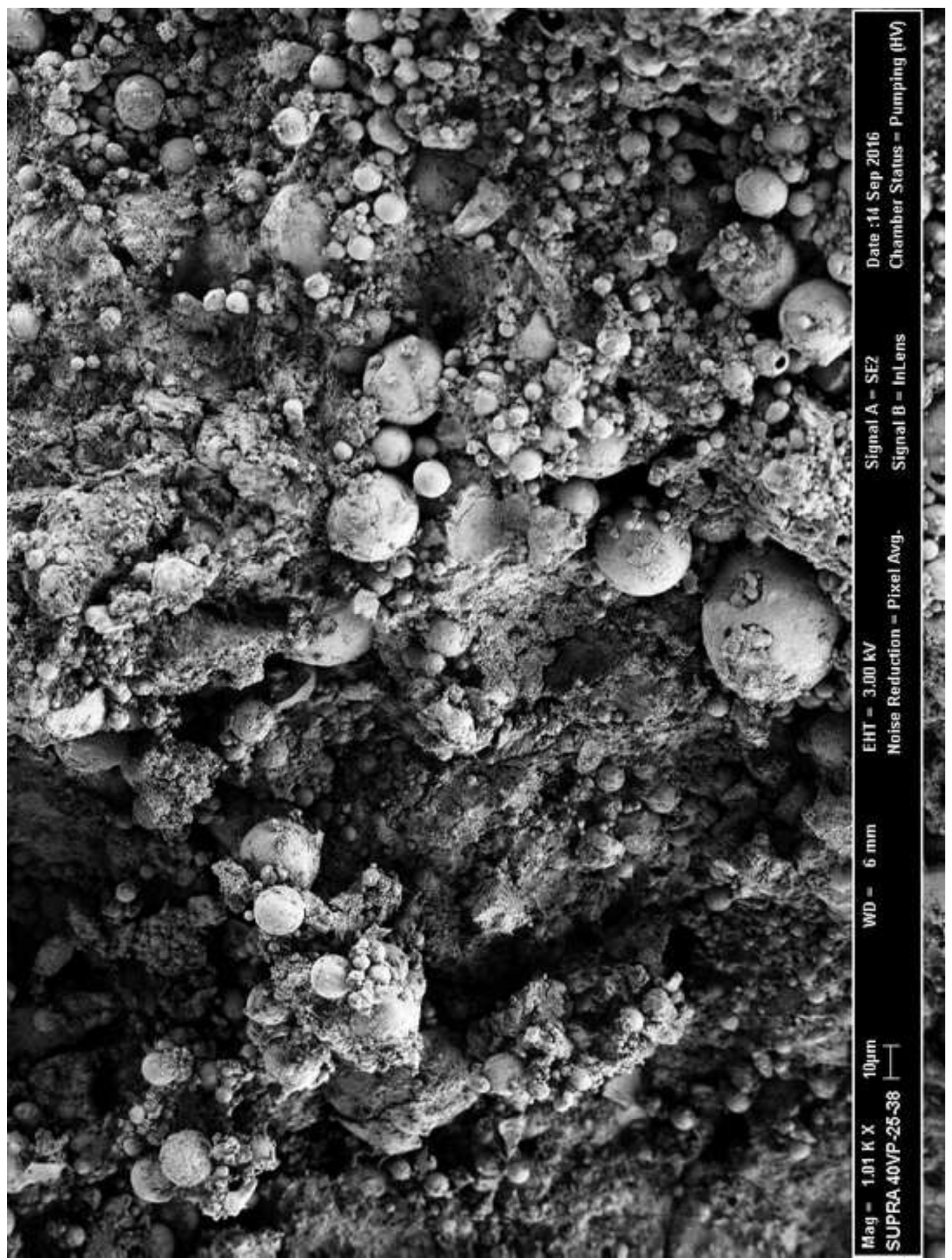




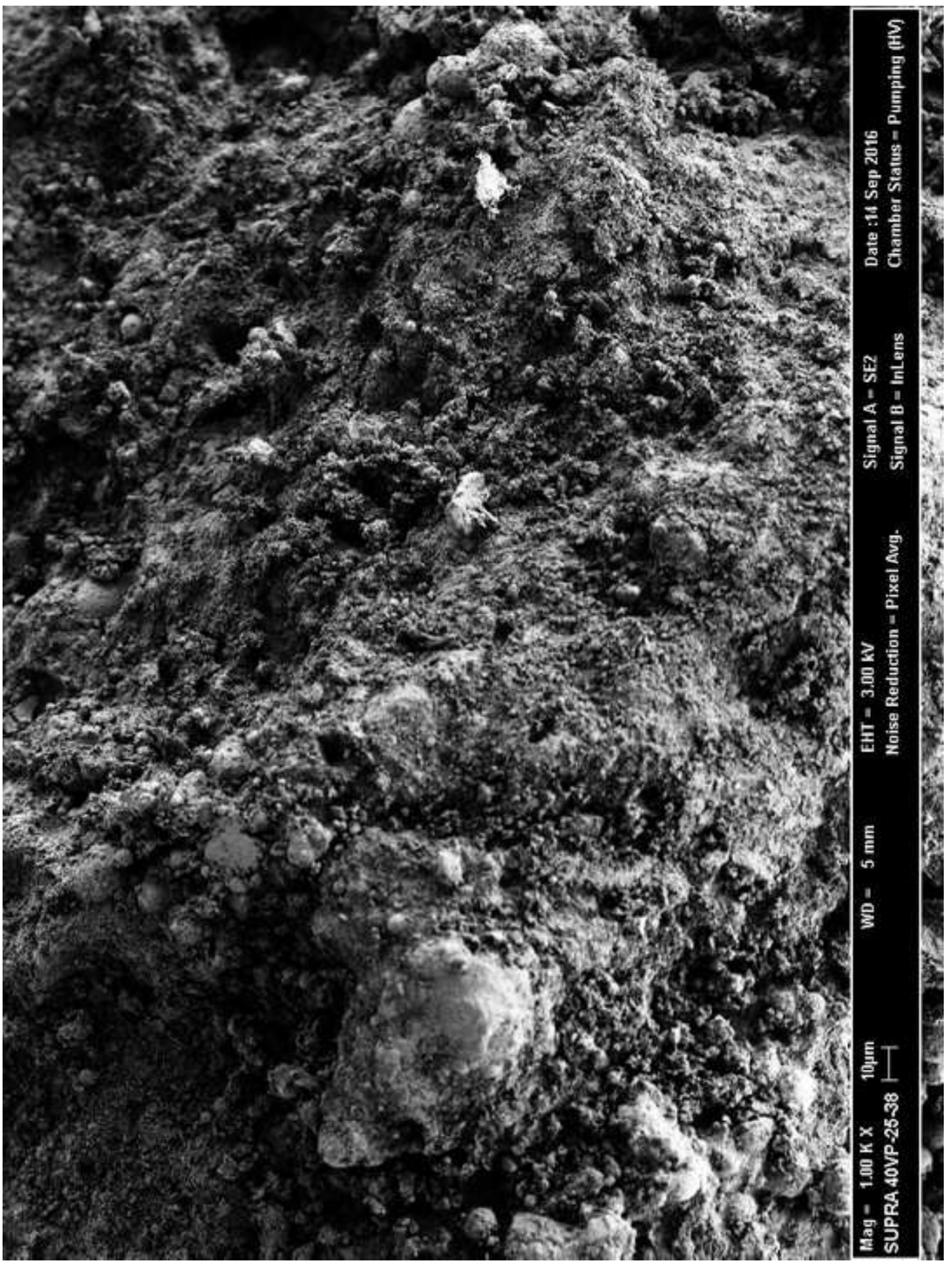




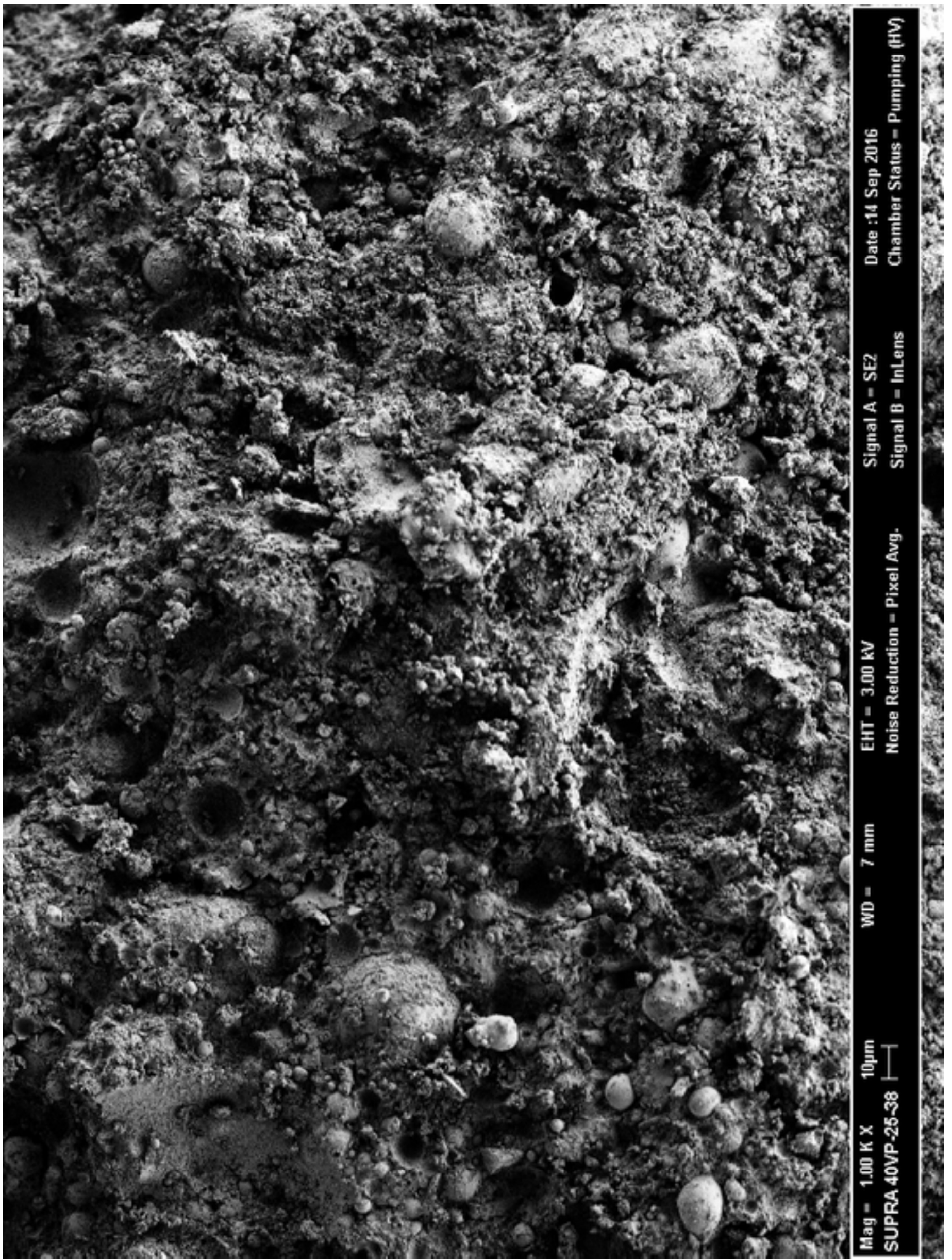

